\title{
Effect of Fastening and of Sensory Stimulation upon the Rate of Epinephrine Output from the Suprarenal Gland in Dogs.
}

The Fourth Report. $\S$

\author{
By \\ YASUTARO SATAKE, MASANOSUKÉ WATANABÉ \\ (佐 武 安太郎) (渡 邊 政之 助) \\ and \\ TADASHI SUGAWARA. \\ (菅原正) \\ (From the Physiological Laboratory, Sendai.)
}

In the foregoing article is presented a method for collecting the blood from the suprarenal gland in the $\mathrm{dog}$, while the animal is freely sitting, standing, eating, drinking or furthermore sleeping. Namely the behavior of the animal under experimental conditions inherent in that method apparently differs but little from its natural, daily life.

It seems now desirable to test the influence of various kinds of agencies upon the epinephrine discharge from the suprarenal body under such experimental conditions as would allow of an honest appearance of the effect of that agency to be examined without undergoing any modification.

The present paper, the first report of this series of experiments performed with this new method, deals with the results of experiments of fastening down the dog on the board and of sensory stimulation. As both the manipulations have yielded somewhat different features in respect of accelerating the epinephrine output both as to the constancy of occurrence and the degree of the acceleration, they will be taken up separately and in the order named.

$\S$ The essentials of this paper was read before the V. Jap. Physiological Meeting at Tokyo, 1926 April (J. Biophysics, 1927, 2, in the press.).

1) Yasu. Satake, Tadashi Sugawara and Masa. Watanabé, Tohoku J. Exp. Med., 1927, 8, 501. 


\section{I.}

In contrast with the numerous investigations on the fastening diabetes, for an account of which we may refer to a paper of $\mathrm{Fujii,9}$ any study of the influence exercised by the fastening down of the animal upon its epinephrine liberation has hitherto been wanting however.

The new method introduced by the foregoing communication affords indubitably an ideal background against which the effect of fastening down may be tested with ease and confidence.

It is scarcely necessary to say that the general method used in the present investigations was that outlined in the preceding paper.

Some dogs which were beforehand de-afferented for the cava pocket experiments, that is, the dorsal roots from the VI thoracic to the II lumbar cord of which were previously sectioned, came also into application in the present investigations. In some other dogs the region corresponding to the $\mathrm{X}$ thoracic to the $\mathrm{II}$ lumbar cord was de-afferented. Since it was found however insufficient in one case where the incision through the skin and muscle was widened further backward than usual in order to place properly the glass cylinder for collection of blood under the opening of the cannula inserted into the proximal portion of the lumbar vein, which pointed in this instance much more caudally than usually, the III lumbar dorsal roots were henceforth severed as a rule in addition to the six pairs of roots, with satisfactory results.

In almost half of the instance listed in the table, the so de-afferented dog was first fastened down on the dog board, and the lumbar route operation was then carried out on the fistened dog. As already related on another occasion 1 the excessive deepening of breathing attendant upon the fastening down of the animal seriously interfered with the minute preparations involved in this operation, as ligating small veins, inserting the small cannula, etc. In the rest the lumbar route operation was carried out while the dog was freely sitting or standing on the table without any restraining. We soon came to see the adequency of the free, natural posture of the animal for such an operation.

The epinephrine content of the blood samples was estimated by means of the rabbit intestine segment method. ${ }^{3}$ ) In some instances we attempted to assay it by means of the denervated eye of cat, fully illustrated in a previous publication, 4 ) but in vain. Not only in the blood specimens collected during intervals of quiet, but also in those taken during restless spells evoked by fastening down as well as by sensory stimulation epinephrine was contained usually in indeterminable amounts with the latter reaction (with 1-2 c.c. blood). This fact is to be contrasted with the previous works in which we were able to make use of the denervated pupil method with satisfaction, and in reality for the cava pocket specimens from the animals, without reference to their being subjected to anaesthesia or not. $\left.{ }^{5}\right)$ Other-

2) Iju. Fuji i, Tôhoku J. Exp. Med., 1921, $2,9$.

3) Tadashi Sugawara, Masa. Watanabé and Shidzuka Saito, Tôhoku J. Exp. Med., 1926, 7, 6 ff.

.4) Tadashi Sugaw a r a, Ibid., 1927, 8, 357-370.

5) (3) p. 67 ; (4) p. 383-402. 
wise expressed, these results indicate plainly a far lower epinephrine concentration of the suprarenal vein bloods collected by the lumbar way from not-anaesthetized dogs, even during sensory stimulation, in comparison with the cara pocket samples; to this we will refer again later.

Fastening experiments, 23 in number, were carried out on 13 dogs. The dog was fastened prone on the table by means of a metallic head holder and heavy strings for the limbs. It is needless to add that anaesthesia was never resorted to.

The fastening was reflected with violent reactions-yelling, snarling or plaintive vocalization, struggling to get free from fastening by retracting of the head with some wrenching from side to side, alternative moving to and fro of the four limbs, and lashing of the tail, provided the latter was not bound to a hind limb, and also sometimes micturition-in $16 \mathrm{ob}-$ servations with ten dogs, while the agitating manifestations failed to occur in four observations in Dogs $9 \& 13$ and occurred only slightly in Dog 6 . Breathing became deeper and respiratory undulation of the heart beats remarkably evident, regardless of whether it was already obvious or not during the rest intervals. In some cases the fastening was reacted by a body temperature rise of a small degree.

Since in most cases the dogs were utilized for the sensory stimulation at the same time with the fastening experiments, the results on both kinds of experiments are displayed together in one table.

As an example of accelerating influence of the fastening upon the epinephrine discharge the protocoll of $\operatorname{Dog} 8$ may be placed on record in full detail.

\section{TABLE.}

Effect of fastening and sensory stimulation upon epinephrine output.

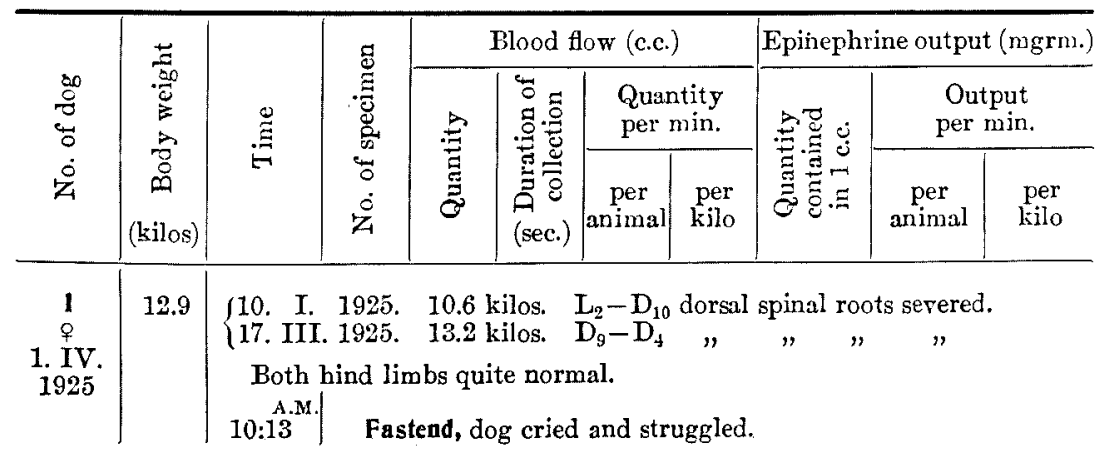




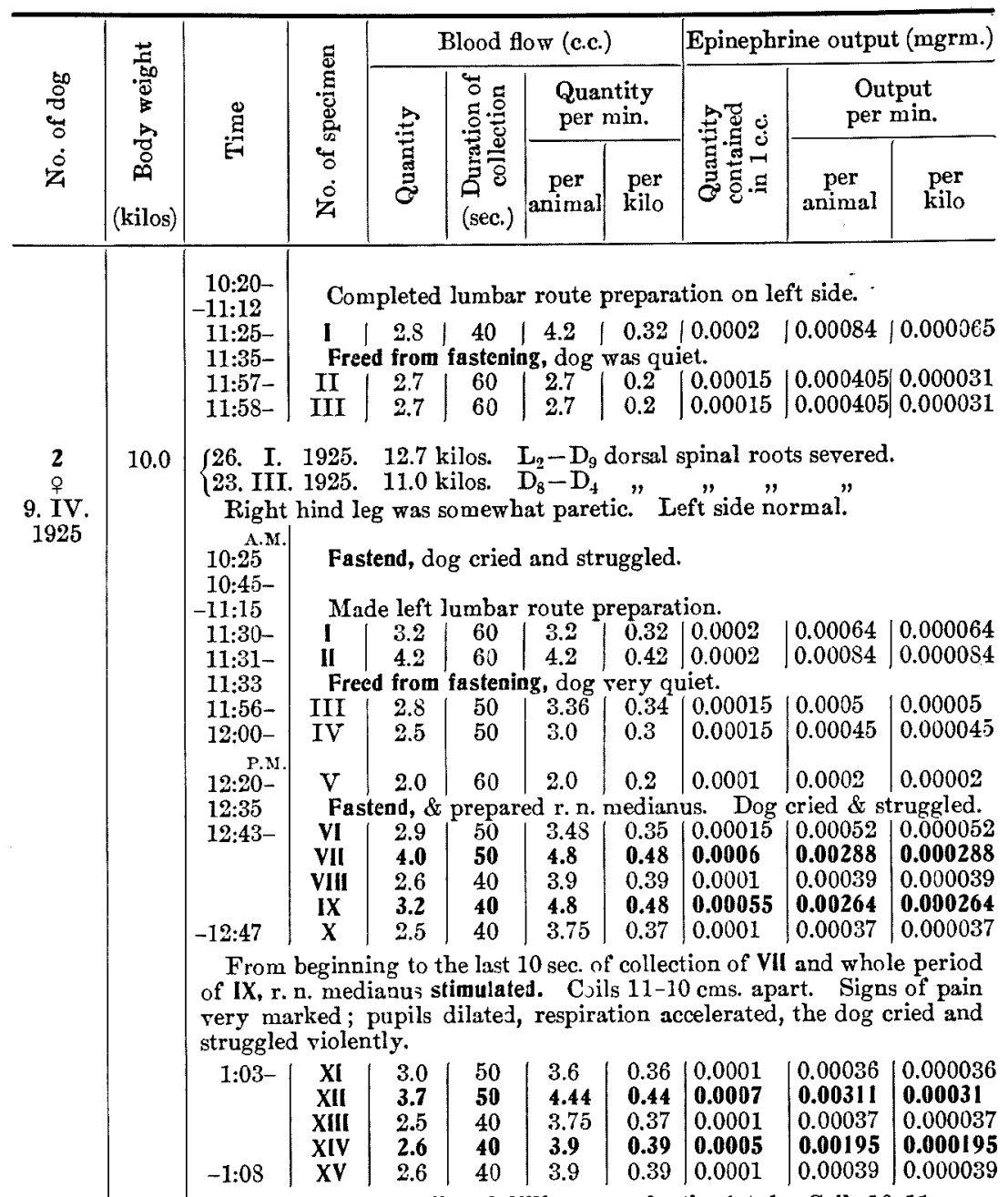

Whole period of XII and XIV r. n. med. stimulated. Coils 10-11 cms. apart. Reactions against stimulation very violent.

(13. I. 1925. 10 kilos. $\mathrm{L}_{2}-\mathrm{D}_{9}$ dorsal spinal roots severed.

i24. III. 1925. 11 kilos. $\mathrm{D}_{3}^{-}-\mathrm{D}_{1}, "$ " " "

Hind legs comewhat paretic.

A.M. 10:34 $10: 50-$

P.M.
$-12: 23$
$12: 30$
$1: 05$
$1: 17-$
$1: 19-$
$1: 35$

Fastend. Dog struggled and cried.

Completed left lumbar-route preparation.

Freed head.

Fastened head, struggled.

\begin{tabular}{l|l|l|l|l|l|l|l|l} 
I & 2.0 & 60 & 2.0 & 0.18 & $0.0001-$ & $0.0002-$ & $0.000018-$ \\
II & 1.9 & 60 & 1.9 & 0.17 & $0.0001-$ & $0.00019-$ & $0.000017-$
\end{tabular} Set free from fastening. Dog stand quiet. 


\begin{tabular}{|c|c|c|c|c|c|c|c|c|c|c|}
\hline \multirow{3}{*}{$\begin{array}{l}00 \\
0 \\
0 \\
0 \\
0 \\
0 \\
z\end{array}$} & \multirow{3}{*}{ 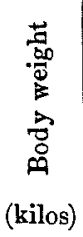 } & \multirow{3}{*}{ 萤 } & \multirow{3}{*}{ 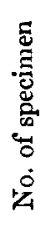 } & \multicolumn{4}{|c|}{ Blood flow (c.c.) } & \multicolumn{3}{|c|}{ Epinephrine output (mgrm.) } \\
\hline & & & & \multirow{2}{*}{ 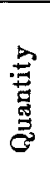 } & \multirow{2}{*}{ 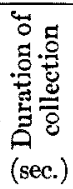 } & \multicolumn{2}{|c|}{$\begin{array}{l}\text { Quantity } \\
\text { per min. }\end{array}$} & \multirow{2}{*}{ 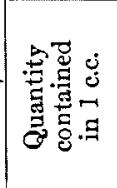 } & \multicolumn{2}{|c|}{$\begin{array}{l}\text { Output } \\
\text { per min. }\end{array}$} \\
\hline & & & & & & $\begin{array}{c}\text { per } \\
\text { animal }\end{array}$ & $\begin{array}{l}\text { per } \\
\text { kilo }\end{array}$ & & $\underset{\text { animal }}{\text { per }}$ & $\begin{array}{l}\text { per } \\
\text { kilo }\end{array}$ \\
\hline & 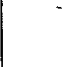 & $\begin{array}{l}2: 00- \\
2: 04-\end{array}$ & $\begin{array}{l}\text { III } \\
\text { IV }\end{array}$ & $\begin{array}{l}0.8 \\
1.2\end{array}$ & $\begin{array}{l}90 \\
90\end{array}$ & $\begin{array}{l}0.53 \\
0.8\end{array}$ & $\begin{array}{l}0.05 \\
0.07\end{array}$ & $\begin{array}{l}0.000175 \\
0.00015\end{array}$ & $\begin{array}{l}0.000093 \\
0.00012\end{array}$ & $\begin{array}{l}0.000008 \\
0.000011\end{array}$ \\
\hline & & $2: 36$ & & & prepa & $\operatorname{red} \mathbf{r} \cdot \mathrm{n}$ & & & & \\
\hline & & $3: 10-$ & $\begin{array}{l}\text { V } \\
\text { VI }\end{array}$ & 0.5 & 90 & $\begin{array}{l}0.33 \\
0.47\end{array}$ & $\begin{array}{l}0.02 \\
0.04\end{array}$ & $\begin{array}{l}0.0002 \\
\mathbf{0 . 0 0 0 4}\end{array}$ & $\begin{array}{l}0.000066 \\
\mathbf{0 . 0 0 0 1 8 8}\end{array}$ & $\begin{array}{l}0.000006 \\
0.000017\end{array}$ \\
\hline & & $-3: 15$ & VII & 0.9 & 90 & 0.6 & 0.05 & 0.0001 & 0.00006 & 0.00000 \\
\hline
\end{tabular}

From beginning to the last 15 sec. of collection of VI, right n. med. stimulated. Coils $10 \mathrm{cms}$. apart. Reactions to stimulation very violent.

15. $\stackrel{4}{\hat{\delta}}$

$15 . \mathrm{V}$

5

s

12. VI.

1925

12.5

f 6. III. 1925. 14 kilos. $\mathrm{L}_{2}-\mathrm{D}_{11}$ dorsal spinal roots severed.

120. IV. 1925. 14.2 kilos. $\mathrm{D}_{10}-\mathrm{D}_{b}$ "

Hind legs normal.

A.M.
$9: 30$
$9: 45-$

Fastend, dog cried and struggled.

$11: 07-$

$-11: 09$

$11: 13$

$11: 34$

$-11: 36$

11:51-

Made left lumbar route operation. cried and struggled to try get free from fastening.

\begin{tabular}{l|l|l|l|l|l|l|l|l|l|l|l|l|l|} 
I & 1.9 & 60 & 1.9 & 0.15 & $0.0001-$ & $0.00019-$ & $0.00015-$
\end{tabular} \begin{tabular}{l|l|l|l|l|l|l|l|l} 
II & 1.8 & 60 & 1.8 & 0.14 & $0.0001-$ & $0.00018-0.000014-$
\end{tabular} Freed from fastening, dog very calm.

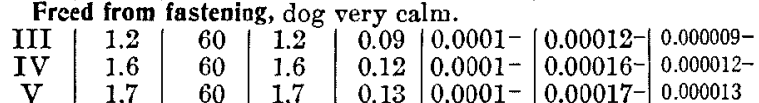

f17. IV. 1925. 14.7 kilos. $\mathrm{L}_{2}-\mathrm{D}_{10}$ dorsal spinal roots severed.

18. V. 1925. 13.6 kilos. $\mathrm{D}_{9}-\mathrm{D}_{4}, ", "$ "

Both hind limbs somewhat paretic.

A.M.
$9: 25$
$9: 30$
$-10: 13$
$10: 37-$
$10: 40-$
$10: 55$
$11: 29-$
$11: 33-$
$11: 38$
$12: 00 \mathrm{Mr}$.
P.M.
$12: 18-$
$-12: 22$

Fastend, dog cried and struggled throughout the fastening.

Completed left lumbar route operation.

\begin{tabular}{l|l|l|l|l|l|l|l} 
I & 2.9 & 120 & 1.45 & 0.11 & 0.0002 & 0.00029 & 0.000023 \\
& 2.6 & 120 & 1.3 & 0.1 & - &
\end{tabular}

Freed from fastening, dog stand quiet.

\begin{tabular}{l|l|l|l|l|l|l|l} 
II & 2.5 & 120 & 1.25 & 0.1 & 0.0002 & 0.00025 & 0.000019 \\
II' & 2.3 & 120 & 1.15 & 0.09 & - &
\end{tabular}

Fastend, dog struggled and cried.

Prepared r. n. auricularis mag.

III was collected without stimulation and IV with stimulation. Coils $\mathrm{S}$ cros. apart. Reactions to stimulation very violent.

\begin{tabular}{r|l|l|l|l|l|l|l|l}
$\mathbf{1 2} 253-$ & $\mathbf{V}$ & 2.8 & 120 & $\mathbf{1 . 4}$ & 0.11 & 0.00025 & 0.00035 & 0.000027 \\
$-12: 57 \frac{2}{3}$ & VI & $\mathbf{2 . 1}$ & $\mathbf{1 0 0}$ & $\mathbf{1 . 2 6}$ & $\mathbf{0 . 1}$ & $\mathbf{0 . 0 0 0 4}$ & $\mathbf{0 . 0 0 0 5 0 4}$ & $\mathbf{0 . 0 0 0 0 3 9}$
\end{tabular}

V was collected without stimulation and VI with stimulation. Coils

8 cms. apart. Reactions to the stimulation very violent.

\begin{tabular}{r|r|r|r|l|l|l|l|l}
$1: 05-$ & VII & 2.0 & 120 & 1.0 & 0.08 & 0.0003 & 0.0003 & 0.000023 \\
$-1: 09 \frac{1}{2}$ & VIII & $\mathbf{2 . 9}$ & $\mathbf{9 0}$ & $\mathbf{1 . 9 3}$ & $\mathbf{0 . 1 5}$ & $\mathbf{0 . 0 0 0 5}$ & $\mathbf{0 . 0 0 0 9 6 5}$ & $\mathbf{0 . 0 0 0 0 7 4}$
\end{tabular}

VII: Without stimulation, VIII: With stimulalion. Coils 8 cms. apart.

Reactions very violent. 


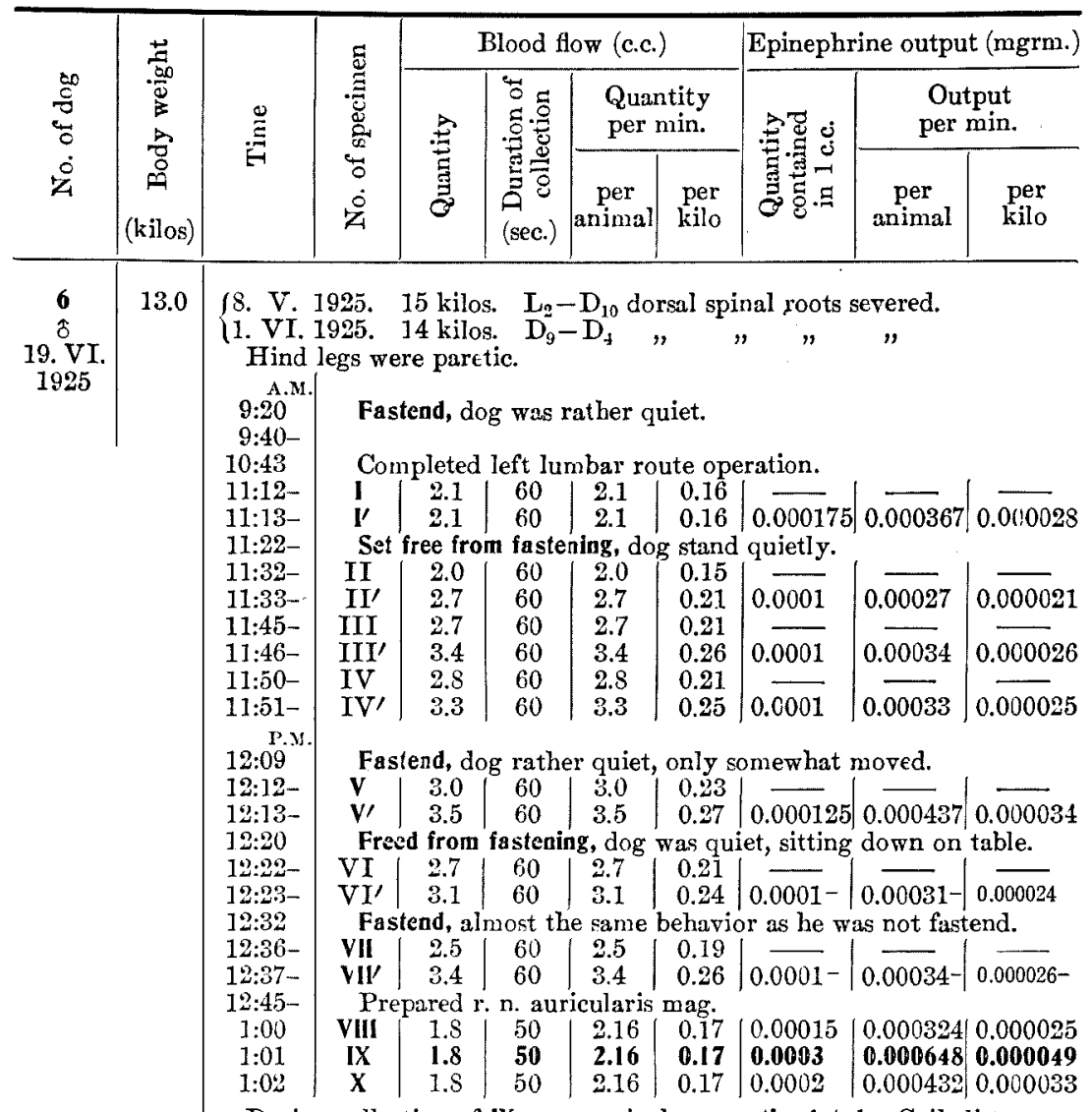

During collection of IX, r. n. auricul. mag. stimulated. Coil distance :

$11 \mathrm{cms}$. Reactions to stimulation very marked.

\begin{tabular}{l|l|l|l|l|l|l|l|l|}
$1: 17-$ & XI & 2.7 & 50 & 3.24 & 0.25 & 0.0001 & 0.000324 & 0.000025 \\
$1: 18-$ & XII & $\mathbf{2 . 7}$ & $\mathbf{5 0}$ & $\mathbf{3 . 2 4}$ & $\mathbf{0 . 2 5}$ & $\mathbf{0 . 0 0 0 1 5}$ & $\mathbf{0 . 0 0 0 4 8 6}$ & $\mathbf{0 . 0 0 0 0 3 7}$ \\
$1: 19-$ & XIII & 2.9 & 50 & 3.48 & 0.26 & 0.0001 & 0.000248 & 0.000026 \\
$1: 20-$ & XIV & $\mathbf{3 . 1}$ & $\mathbf{5 0}$ & $\mathbf{3 . 7 2}$ & $\mathbf{0 . 2 9}$ & $\mathbf{0 . 0 0 0 1 5}$ & $\mathbf{0 . 0 0 0 5 5 8}$ & $\mathbf{0 . 0 0 0 0 4 3}$ \\
$1: 22-$ & XV & 2.9 & 50 & 3.48 & 0.26 & 0.0001 & 0.000348 & 0.000026
\end{tabular}

During collection of XII and XIV, r. n. auricul. mag. stimulated. Coils $10 \mathrm{cms}$. apart. Reactions to stimulation very violent.

11. V. 1925. 14.5 kilos. $\mathrm{I}_{2}-\mathrm{D}_{10}$ dorsal spinal roots severed.

15. Vi. 1925. 12.5 kilos. $\mathrm{D}_{3}-\mathrm{D}_{4}, ", "$ Hind legs were paretic.

A.M. $9: 12$

$9: 30-$

$-10: 10$

$10: 33-$

$10: 34$

$10: 44$

$10: 54-$
Fastend. Dog cried and struggled very furiously and uninterruptedly throughout fastening.

Made left lumbar route.

\begin{tabular}{l|l|l|l|l|l|l|l} 
II & 2.9 & 60 & 2.9 & 0.23 & 0.01375 & 0.03987 & 0.00315 \\
II & 3.0 & 60 & 3.0 & 0.23 & 0.04125 & 0.00322
\end{tabular}

Freed from fastening, dog became very quiet.

III $|2.9| 60|2.9| 0.23|0.00015| 0.000435 \mid 0.000034$ 


\begin{tabular}{|c|c|c|c|c|c|c|c|c|c|c|}
\hline \multirow{3}{*}{$\begin{array}{l}20 \\
0 \\
0 \\
0 \\
0 \\
\dot{2}\end{array}$} & \multirow{3}{*}{ 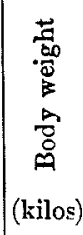 } & \multirow{3}{*}{ 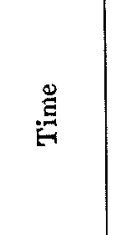 } & \multirow{3}{*}{ 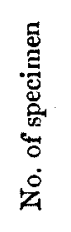 } & \multicolumn{4}{|c|}{ Blood flow (c.c.) } & \multicolumn{3}{|c|}{ Epinephrine output (mgrm.) } \\
\hline & & & & \multirow{2}{*}{ 苞 } & \multirow{2}{*}{ 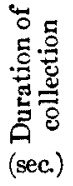 } & \multicolumn{2}{|c|}{$\begin{array}{l}\text { Quantity } \\
\text { per min. }\end{array}$} & \multirow{2}{*}{ 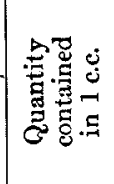 } & \multicolumn{2}{|c|}{$\begin{array}{l}\text { Output } \\
\text { per min. }\end{array}$} \\
\hline & & & & & & $\begin{array}{c}\text { per } \\
\text { animal }\end{array}$ & $\begin{array}{l}\text { per } \\
\text { kilo. }\end{array}$ & & $\begin{array}{c}\text { per } \\
\text { animal }\end{array}$ & $\begin{array}{l}\text { per } \\
\text { kilo }\end{array}$ \\
\hline \multirow{40}{*}{ 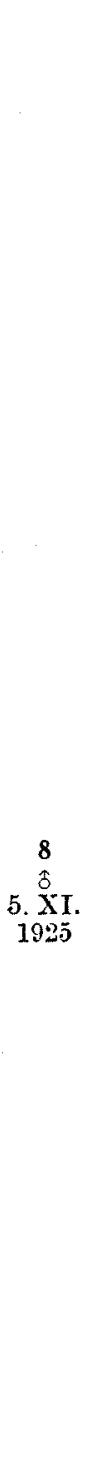 } & \multirow{40}{*}{14,0} & $\begin{array}{l}10: 55- \\
10: 56-\end{array}$ & IV & $\begin{array}{l}3.0 \\
3.0\end{array}$ & $\begin{array}{l}60 \\
60\end{array}$ & $\begin{array}{l}3.0 \\
3.0\end{array}$ & $\begin{array}{l}0.23 \\
0.23\end{array}$ & 0.00015 & $\begin{array}{l}0.00045 \\
0.00045\end{array}$ & $\begin{array}{l}0.000035 \\
0.000035\end{array}$ \\
\hline & & $1: 15-$ & \multirow{2}{*}{\multicolumn{8}{|c|}{$\begin{array}{l}\text { Made right lumbar route preparation on non ffastened dog. } \\
\text { Dog very quiet. No signs of pain during operation. }\end{array}$}} \\
\hline & & $\begin{array}{l}-2: 12 \\
2: 25\end{array}$ & & & & & & & & \\
\hline & & $2: 26-$ & VII & 4.8 & 60 & 4.8 & 0.38 & 0.00015 & 0.00072 & 0.000056 \\
\hline & & $2: 32-$ & VIII & 4.4 & 60 & 4.4 & 0.34 & 0.00015 & 0.00066 & 0.000051 \\
\hline & & $2: 34$ & IX & 4.6 & 60 & 4.6 & 0.36 & 0.00015 & 0.00069 & 0.000053 \\
\hline & & & \multicolumn{8}{|c|}{ Fastend, dog cried and struggled rery violently. } \\
\hline & & 2:48- & $\mathbf{X}$ & 4.5 & 60 & $4.5 \mid$ & 0.35 & 0.00025 & 0.001125 & $0.0000 \$ 7$ \\
\hline & & $2: 49-$ & $\mathbf{X I}$ & 3.8 & 60 & 3.8 & 0.3 & 0.0003 & 0.00114 & 0089 \\
\hline & & $\begin{array}{l}2: 5 S^{-} \\
-3: 05\end{array}$ & \multicolumn{8}{|c|}{ Prepared r. n. auricularis mag. Signs of pain marked. } \\
\hline & & $3: 10-$ & XII & 3.1 & 60 & 3.1 & 0.24 & 0.00045 & 0.001395 & $0.00010 \mathrm{~s}$ \\
\hline & & $3: 11 \frac{1}{4}$ & XIII & 2.4 & 50 & 2.88 & 0.22 & 0.0 & 0.0 & \\
\hline & & $3: 12^{1}-$ & & & 60 & & 0.17 & 0.00025 & 0.00055 & $00 J 43$ \\
\hline & & $\begin{array}{l}\text { From } \\
\text { mulated. } \\
\text { strugglin }\end{array}$ & \multicolumn{8}{|c|}{$\begin{array}{l}\text { Coil distance : } 10-9 \text { cms. Signs of pain marked : Crying, } \\
\text { ng and excited respiration and pupil dilation. }\end{array}$} \\
\hline & & $3: 15-$ & $\mathrm{XV}$ & 3.5 & 60 & $3.5 \mid$ & 0.29 & 0.00025 & 0.000575 & $0.00006 \mathrm{~S}$ \\
\hline & & $3: 161$ & XVI & 3.0 & 50 & 3.6 & 0.29 & 0.0 & 0.0 & \\
\hline & & $3: 18_{\frac{2}{2}-1}^{2}$ & XVII & 2.7 & 60 & 2.7 & 0.21 & 0.0003 & 0.0 & 063 \\
\hline & & \multicolumn{9}{|c|}{$\begin{array}{l}\text { From beginning to the last } 5 \text { sec. of XVI, r. n. auricul. mag. was stimulated. } \\
\text { Reactions to stimulation were also very violent. Coils } 8 \mathrm{cms} \text {. apart. }\end{array}$} \\
\hline & & $3: 23$ & \multirow{2}{*}{\multicolumn{8}{|c|}{ Freed from fastening, dog quiet. }} \\
\hline & & $3: 45-$ & XVIII & & & & & & & \\
\hline & & & XIX & 2.9 & 60 & 2.9 & 0.23 & & & \\
\hline & & \multicolumn{9}{|c|}{ 17. IX. 1925. 13.7 kilos. $L_{2}-D_{10}$ dorsal spinal roots serered. } \\
\hline & & & $\mathrm{Ma}$ & e left & lemba & route & withon & & Tinos & Teserv \\
\hline & & $-12: 00$ & quiet & & Inonst & e operat & ion. & a lasteumg & 5. Dog & wh very \\
\hline & & P:01- & I & 3.4 & 40 & 5.1 & 0.36 & $0.00005^{-}$ & $0.000255-$ & $0.000018-$ \\
\hline & & $1: 01 \frac{1}{3}$ & $I^{\prime}$ & 3.3 & 40 & 4.95 & 0.35 & 0.000075 & 0.000371 & 0.000026 \\
\hline & & $1: 17-$ & II & 2.8 & 40 & 4.2 & 0.3 & 0.0001 & 0.00042 & 0.00003 \\
\hline & & $1: 17 \frac{3}{4}-$ & $\mathrm{II}^{\prime}$ & 3.0 & 40 & 4.5 & 0.32 & 0.000075 & 0.000337 & 0.000024 \\
\hline & & $1: 25$ & Fas & ad, dc & cried & $\mathrm{ad} \mathrm{s}$ & ggled & violently. & & \\
\hline & & $1: 34-$ & III & 3.4 & 40 & 5.1 & 0.36 & 0.0002 & & \\
\hline & & 1:345- & III' $^{\prime}$ & 3.2 & 40 & 4.8 & 0.34 & 0.0002 & 0.00096 & 0.000069 \\
\hline & & $1: 52$ & & from & isten & $\operatorname{dog}$ & ied ve & & & \\
\hline & & $2: 19-$ & IV & 2.3 & 40 & 3.45 & 0.24 & 0.000175 & & 0.0000 \\
\hline & & $2: 195$ & IV' & 3.0 & 50 & 3.6 & 0.25 & 0.000175 & 0.0000 & 0.000043 \\
\hline & & $2: 32$ & Fas & nd, $d$ & crie & and : & iggled & & & \\
\hline & & $2: 34-$ & & 2.8 & 40 & 4.2 & 0.3 & 0.0002 & & \\
\hline & & $2: 345-$ & $v^{\prime}$ & 2.5 & 40 & 3.75 & 0.27 & 0.0002 & 0.00075 & 0.000054 \\
\hline & & & $\begin{array}{l}\text { Fre } \\
\text { tion }\end{array}$ & VI & & e was & Ieepin & riv aujet & & \\
\hline & & $3: 00-$ & VI & 1.5 & 60 & 1.5 & 0.11 & 0.0001 & & 011 \\
\hline & & & $\mathrm{VI}^{\prime}$ & 1.8 & 60 & 3.8 & 0.13 & 0.0501 & 0.00018 & 0.000012 \\
\hline
\end{tabular}




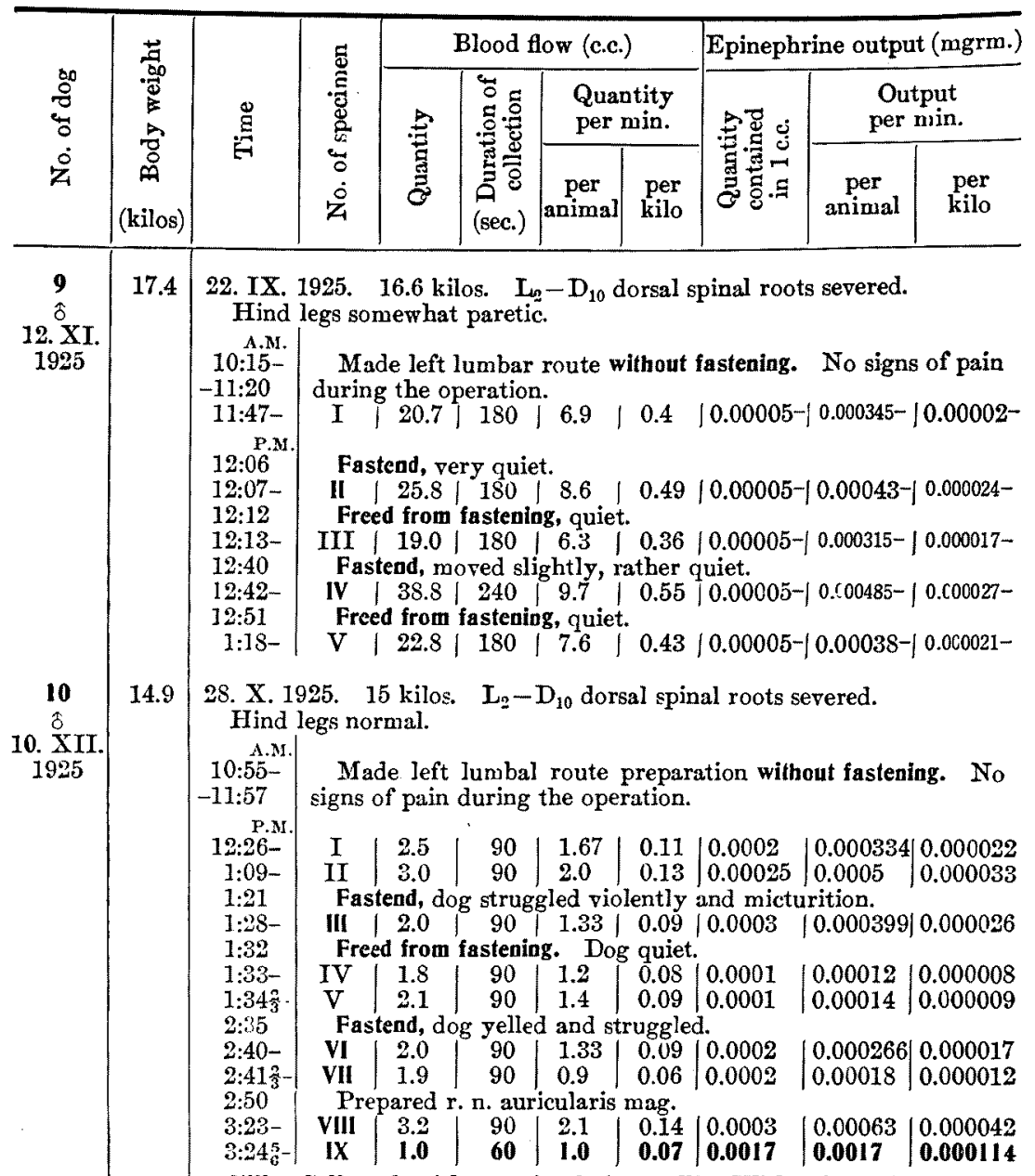

VIII : Collected without stimulation. IX: With stimulation. Coil distance: $9 \mathrm{cms}$. Reactions to stimulation very violent.

\begin{tabular}{l|l|l|l|l|l|l|l|l}
$3: 37-$ & $\mathbf{X}$ & 0.9 & 60 & 0.9 & 0.06 & 0.0005 & 0.00045 & 0.00003 \\
$3: 38_{2}^{-}$ & $\mathbf{X I}$ & $\mathbf{1 . 0}$ & $\mathbf{6 0}$ & $\mathbf{1 . 0}$ & $\mathbf{0 . 0 7}$ & $\mathbf{0 . 0 0 2 5}$ & $\mathbf{0 . 0 0 2 5}$ & $\mathbf{0 . 0 0 0 1 6 7}$
\end{tabular}

$X$ : Collected without stimulation. XI: With silimulation. Coil distance : $8.5 \mathrm{cms}$. Reactions to stimulation very violent.

25.0

12. X. 1925. 26.6 kilos. $\mathrm{L}_{2}-\mathrm{D}_{11}$ dorsal spinal roots severed.

Hind legs somewhat paretic.

A.M.

Made left lumbar route preparation without fastening. At

P.M, manipulation around the central end of suprarenal vein some-

$-12: 35$ what sensitive.

\begin{tabular}{l|l|l|l|l|l|l|l|l|l|}
$1: 34-$ & & 5.5 & 60 & 5.5 & 0.22 & 0.000125 & $0.000687 \mid$ & 0.0600275
\end{tabular}

1:45 Fastend, dog cried, struggled and urinated.

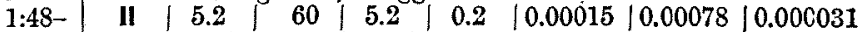

1:58- Prepared r. n. auricularis mag. 


\begin{tabular}{|c|c|c|c|c|c|c|c|c|c|c|}
\hline \multirow{3}{*}{$\begin{array}{l}00 \\
\ddot{8} \\
\ddot{0} \\
\dot{0} \\
\ddot{4}\end{array}$} & \multirow{3}{*}{ 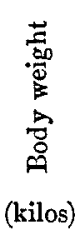 } & \multirow{3}{*}{$\stackrel{\mathscr{D}}{\Xi}$} & \multirow{3}{*}{ 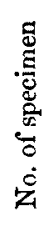 } & \multicolumn{4}{|c|}{ Blood flow (c.c.) } & \multicolumn{3}{|c|}{ Epinephrine output (mgrm.) } \\
\hline & & & & \multirow{2}{*}{ 胥 } & \multirow{2}{*}{ 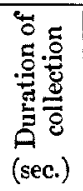 } & \multicolumn{2}{|c|}{$\begin{array}{l}\text { Quantity } \\
\text { per min. }\end{array}$} & \multirow{2}{*}{ 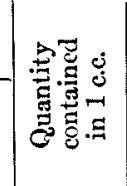 } & \multicolumn{2}{|c|}{$\begin{array}{l}\text { Output } \\
\text { per min. }\end{array}$} \\
\hline & & & & & & $\underset{\text { animal }}{\text { per }}$ & $\begin{array}{l}\text { per } \\
\text { kilo }\end{array}$ & & $\begin{array}{c}\text { per } \\
\text { animal }\end{array}$ & $\begin{array}{l}\text { per } \\
\text { kilo }\end{array}$ \\
\hline \multirow{12}{*}{ 24. $\stackrel{\hat{\delta}}{\mathrm{X}}_{1925}^{12}$} & \multirow{12}{*}{15.5} & $\begin{array}{l}2: 29- \\
2: 55- \\
2: 56- \\
2: 57- \\
2: 58- \\
2: 59-\end{array}$ & $\begin{array}{l}\text { III } \\
\text { IV } \\
\text { V } \\
\text { VI } \\
\text { VII } \\
\text { VIII }\end{array}$ & $\begin{array}{l}5.7 \\
4.5 \\
3.2 \\
3.5 \\
3.3 \\
3.4\end{array}$ & $\begin{array}{l}60 \\
50 \\
\mathbf{5 0} \\
50 \\
\mathbf{5 0} \\
50\end{array}$ & $\begin{array}{l}5.7 \\
5.4 \\
3.8 \\
4.2 \\
4.0 \\
4.1\end{array}$ & $\begin{array}{l}0.22 \\
0.21 \\
0.15 \\
0.16 \\
0.16 \\
0.16\end{array}$ & \begin{tabular}{|l|}
0.00025 \\
0.000225 \\
$\mathbf{0 . 0 0 0 2 7 5}$ \\
0.00025 \\
$\mathbf{0 . 0 0 0 2 7 5}$ \\
0.00025
\end{tabular} & $\begin{array}{l}0.00142 \\
0.001215 \\
0.001045 \\
0.00105 \\
0.00011 \\
0.001025\end{array}$ & $\begin{array}{l}0.000057 \\
0.000049 \\
\mathbf{0 . 0 0 0 0 4 1} \\
0.000042 \\
\mathbf{0 . 0 0 0 0 4 4} \\
0.000041\end{array}$ \\
\hline & & \multicolumn{9}{|c|}{$\begin{array}{l}\text { III, IV, VI and VIII were collected without stimulation and V and VII } \\
\text { with stimulation. Coil distance : At V } 11 \mathrm{cms} \text {. and at VII } 10 \mathrm{cms} \text {. Re- } \\
\text { actions to stimulation very violent; respiration became faster, stronger } \\
\text { and deeper; pupils dilated; dog cried and struggled violently, so that } 3 \\
\text { assistants were needed to force down the dog during collection of samples. }\end{array}$} \\
\hline & & \multicolumn{9}{|c|}{$\begin{array}{l}\text { 21. X. } 1925 . \quad 21.5 \text { kilos. } \\
\text { Hind legs normal. }\end{array}$} \\
\hline & & $\begin{array}{c}10: 30- \\
\text { P.M } \\
-12: 15 \\
\text { I:16- } \\
1: 17-\end{array}$ & hind & $\begin{array}{l}\text { e let } \\
\text { gion }\end{array}$ & unsitir & $\begin{array}{l}\text { route } \\
\text { e. }\end{array}$ & ithout & $\left|\begin{array}{l}0.0001- \\
0.0001-\end{array}\right|$ & $\mid \begin{array}{l}0.00025^{-} \\
0.00027-\end{array}$ & $\mid \begin{array}{l}0.000016- \\
0.000017-\end{array}$ \\
\hline & & $1: 31$ & \multicolumn{8}{|c|}{ Fastend, dog cried and struggled violently. } \\
\hline & & $\begin{array}{l}1: 36- \\
1: 37-\end{array}$ & $\begin{array}{l}\text { III } \\
\text { IV }\end{array}$ & $\begin{array}{l}2.5 \\
2.8\end{array}$ & $\begin{array}{l}60 \\
60\end{array}$ & \begin{tabular}{|l|}
2.5 \\
2.8
\end{tabular} & $\begin{array}{l}0.16 \\
0.18\end{array}$ & $\mid \begin{array}{l}0.00015 \\
0.00015\end{array}$ & $\mid \begin{array}{l}0.000375 \\
0.00042\end{array}$ & $\begin{array}{l}0.00002 \\
0.000027\end{array}$ \\
\hline & & $1: 47$ & \multicolumn{8}{|c|}{ Prepared r. n. auricularis mag. } \\
\hline & & 1:58- & V & & 60 & 2.9 & 0.19 & & & \\
\hline & & & VI & & 60 & 3. & & & & \\
\hline & & & VII & & 60 & 2.8 & $0.1 \mathrm{~s}$ & 0.0002 & 0.00056 & 0.000036 \\
\hline & & $2: 02 \frac{1}{3}$ & VIII & 2.8 & 60 & 2.8 & 0.18 & 0.0004 & 0.00112 & 0.00007 \\
\hline & & & IX & 3.0 & 60 & 3.0 & 0.19 & & & \\
\hline
\end{tabular}

V, VII and IX were collected without stimulation. VI and VIII with stimulation. Coils at VI $11-9 \mathrm{cms}$. apart and at VIII $9-8 \mathrm{cms}$. Reactions to stimulation violent.
$2: 56-$
$2: 58-$
$2: 59-$
\begin{tabular}{l|l|}
$\mathbf{X}$ & 2.1 \\
$\mathbf{X I}$ & $\mathbf{2 . 0}$ \\
\hline & $\mathbf{X I}$
\end{tabular}
\begin{tabular}{l|l|}
60 & 2.1 \\
$\mathbf{6 0}$ & $\mathbf{2 . 0}$ \\
60 & 1.5
\end{tabular}
$0.13 \mid 0.0003$
\begin{tabular}{l|l}
0.00063 & 0.0000406 \\
$\mathbf{0 . 0 0 1 8}$ & $\mathbf{0 . 0 0 0 1 1 6}$ \\
0.0003 & 0.00002
\end{tabular}

During collection of $\mathrm{XI}$, a branch of $r$. $n$. auricularis mag. was sti ${ }^{2}$ mulated. Coils 8 cms. apart. Reactions to stimulation very violent.

19. XII. 1925. 20 kilos. $\mathrm{L}_{3}-\mathrm{D}_{10}$ dorsal spinal roots serered.

Hind legs normal.

10:40- Made left lumbar route without fastening. No signs of pain $-11: 35$ throughout the operation.

\begin{tabular}{l|l|l|l|l|l|l|l|l|l|l|l|l|l|l|} 
12:35- & I & 2.3 & 30 & 4 & 0.7 & 0.21 & 0.00005 & 0.00023 & 0.000011
\end{tabular}

$12: 47$

$12: 49-$

$1: 03$

$1: 33-$
$1: 33 \frac{2}{3}$
$1: 35 \frac{1}{3}-$

Fastend, reactions to fastening absent, dog quiet.

II $\mid$\begin{tabular}{l|l|l|l|l|l|l|l|l|l|l|l|l|l|} 
& 2.5 & 30 & 5.1 & 0.23 & 0.00005 & 0.00025 & 0.000012
\end{tabular}

Prepared r. n. auricul. mag. On cutting off the nerve, dog cried, struggled and urinated.

\begin{tabular}{l|l|l|l|l|l|l|l} 
III & 3.1 & 30 & 6.2 & 0.29 & 0.0002 & 0.00124 & 0.000058 \\
IV & $\mathbf{2 . 4}$ & $\mathbf{3 0}$ & $\mathbf{4 . 8}$ & $\mathbf{0 . 2 2}$ & $\mathbf{0 . 0 6 0 5 5}$ & $\mathbf{0 . 0 0 2 6 4}$ & $\mathbf{0 . 0 0 0 1 2 3}$ \\
V & $\mathbf{3 . 3}$ & 30 & 6.6 & 0.31 & 0.0003 & 0.00198 & 0.000092
\end{tabular}




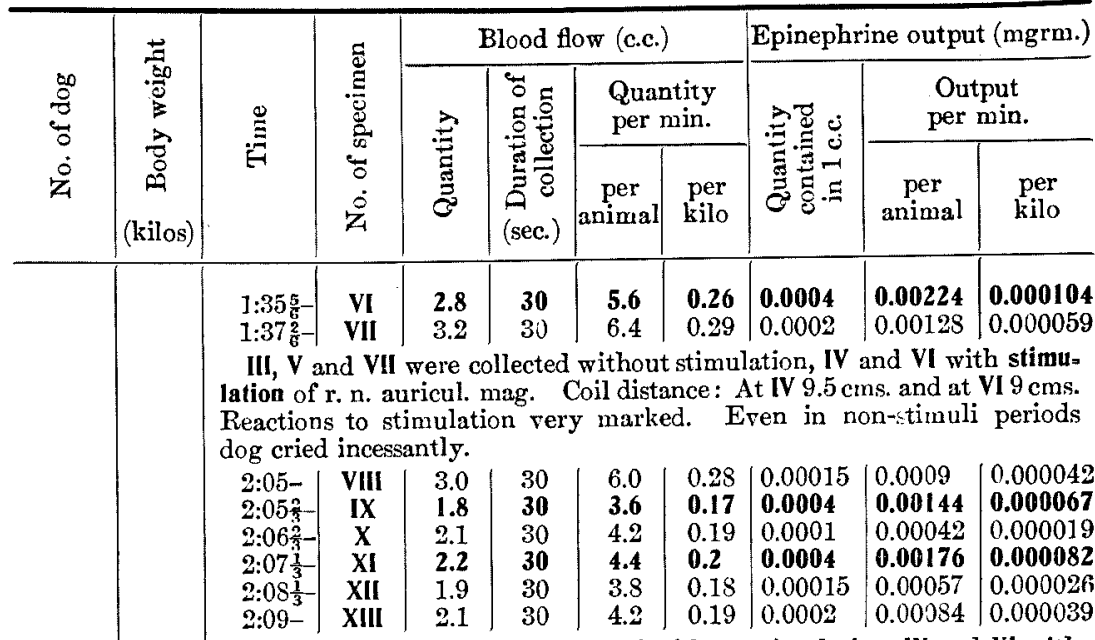

25. I. 1926

21.5

VIII, X, XII and XIII were collected without stimulation, IX and XI with stimulation of $r$. $n$. auricul. mag. Coil distance : At IX $9 \mathrm{cms}$. and at XI $8.5 \mathrm{cms}$. Reactions very violent. Even during non-stimuli periods, dog cried uninterruptedly.

Hind legs normal.

10:35- Made right lumbar route without fastening. No signs of pain $-11: 35$ P.M. throughout the operation.

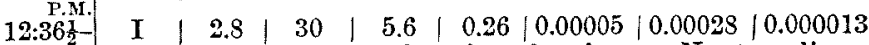

12:48 Fastend, reactions to fastening also absent. No struggling, no crying.

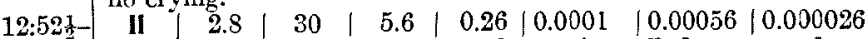

1:22 Prepared r. n. auricul. mag. On cutting off the nerve, dog cried, struggled and micturition.

\begin{tabular}{|c|c|c|c|c|c|c|c|c|}
\hline & III & 98 & 30 & 56 & 096 & & & \\
\hline & III & 2,6 & 30 & 5.2 & 0.24 & 0.000075 & 0.00039 & 0.000018 \\
\hline & IV & 2.2 & 30 & 4.4 & 0.2 & 0.000075 & 0.00033 & 0.000015 \\
\hline & v & 2.0 & 30 & 4.0 & 0.18 & 0.00025 & 0.001 & 0.000046 \\
\hline & VI & 2.8 & 30 & 5.6 & 0.26 & 0.0001 & 0.00056 & 0.000026 \\
\hline & VII & 2. & 30 & 4.2 & 0.19 & 0.00025 & 0.00105 & 0.000048 \\
\hline & VIII & 2.1 & 30 & 4. & 0.19 & 0.00015 & 0.00063 & 0.000029 \\
\hline & VIII' & 2.2 & 30 & 4.4 & 0.2 & 0.00015 & 0.00066 & 0.00003 \\
\hline
\end{tabular}

$\mathrm{V}$ and VIl were collected under stimulation of r. n. auricul. mag. Coils at V $10 \mathrm{cms}$. apart and at VII $9.5 \mathrm{cms}$. Reactions to nerve stimulation very violent; yelling, struggling; pupil dilated and respiration exaggerated. At VI micturition.

\begin{tabular}{|c|c|c|c|c|c|c|c|c|}
\hline $2: 25-$ & IX & 2.4 & 30 & 4.8 & 0.22 & 0.0001 & 0.00048 & 0.000022 \\
\hline 25 & $\mathbf{X}$ & 1.0 & 30 & 2.0 & 0.09 & 0.00055 & 0.0011 & 0.000051 \\
\hline 27 & $\mathbf{X I}$ & 2.0 & 30 & 4.0 & 0.18 & 0.00015 & 0.0006 & 0.000028 \\
\hline & XII & 1.7 & 30 & 3.4 & 0.16 & 0.00035 & 0.00119 & 0.0 \\
\hline & XIII & 2.5 & 30 & 5.0 & 0.23 & 0.00015 & 0.00075 & \\
\hline & \multicolumn{8}{|c|}{ Freed from fastening, dog very quiet. } \\
\hline & XIV & 3.1 & 30 & 6.2 & 0.28 & 0.000 & 046 & \\
\hline & & & 30 & 6.0 & 0.27 & 0.000 & 0.00045 & \\
\hline
\end{tabular}

$X$ and XII were collected under nerre stimulation. Coils at X $9 \mathrm{cms}$. and at XII $8.5 \mathrm{cms}$. apart. Reactions to nerve stimulation were also violent. At $\mathrm{X}$ micturition with struggling. Even during non-stimuli periods, dog cried incessantly and when freed from fastening dog became very calmly, drank milk and ate beaf eagerly. 


\section{Example I.}

$\operatorname{Dog} 8$. 令.

17. IX. 1925. 13.7 kilcs. $\mathrm{L}_{\mathrm{g}}-\mathrm{D}_{10}$ dorsal spinal roots severed.

5. XI. 1925. 14 kilos. Left hind leg somewhat paretic.

Standing and going nearly normal.

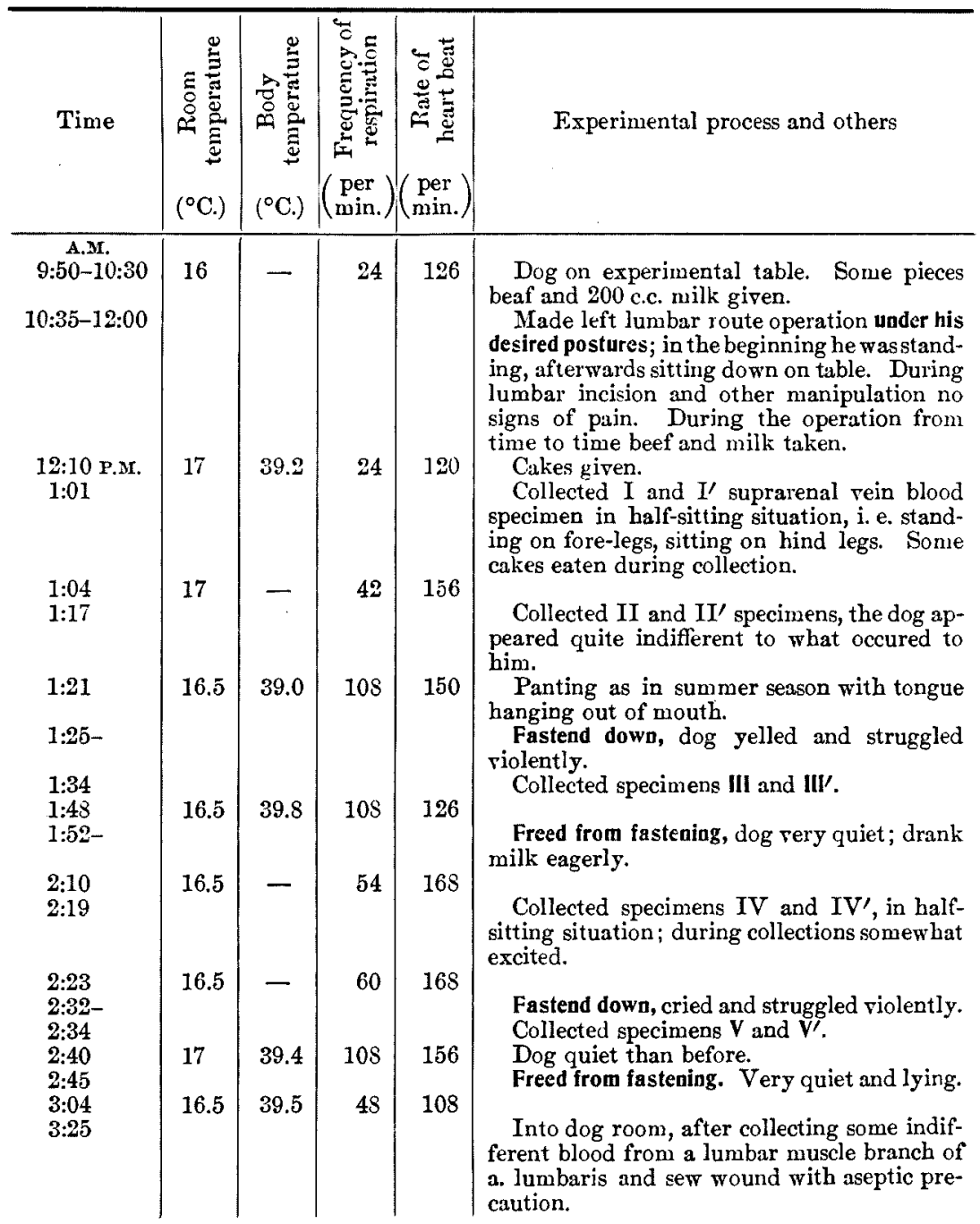


Epinephrine output:

\begin{tabular}{|c|c|c|c|c|c|c|c|c|}
\hline \multirow{3}{*}{ 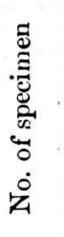 } & \multirow{3}{*}{ Time } & \multicolumn{4}{|c|}{ Blood flow (c.c.) } & \multicolumn{3}{|c|}{ Epinephrine output (mgrm.) } \\
\hline & & \multirow{2}{*}{ 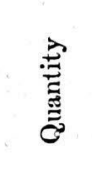 } & \multirow{2}{*}{ 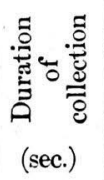 } & \multicolumn{2}{|c|}{$\begin{array}{l}\text { Quantity } \\
\text { per minute }\end{array}$} & \multirow{2}{*}{$\begin{array}{l}\text { Quantity } \\
\text { contained } \\
\text { in } 1 \text { c.c. }\end{array}$} & \multicolumn{2}{|c|}{ Output per minute } \\
\hline & & & & $\begin{array}{c}\text { per } \\
\text { animal }\end{array}$ & $\begin{array}{l}\text { per } \\
\text { kilo }\end{array}$ & & $\begin{array}{c}\text { per } \\
\text { animal }\end{array}$ & $\begin{array}{l}\text { per } \\
\text { kilo }\end{array}$ \\
\hline & P.M. & & & & & & & \\
\hline I & 01- & 3.4 & 40 & 5.1 & 0.36 & $0.00005^{-}$ & $0.000225^{-}$ & $0.000018^{-}$ \\
\hline$I^{\prime}$ & $1: 01 \frac{1}{3}-$ & 3. & 40 & 4.9 & & & 0.000 & 0.000026 \\
\hline II & $1: 17^{3}$ & 2.8 & 40 & 4.2 & 0.3 & 0.0001 & 0.00042 & 0.00003 \\
\hline $\mathrm{II}^{\prime}$ & $1: 17 \frac{3}{4}-$ & 3.0 & 40 & 4.5 & 0.32 & 0.000075 & 0.000337 & 0.000024 \\
\hline & $1: 25$ & Fasten & lown. & & & & & \\
\hline III & $1: 34-$ & 3.4 & 40 & 5.1 & 0.36 & & & 0.000073 \\
\hline III' & $1: 34_{6}^{5-}$ & 3.2 & 40 & 4.8 & 0.34 & 0.0002 & 0.00096 & 0.000069 \\
\hline IV & $\begin{array}{l}1: 52 \\
2: 19-\end{array}$ & $\begin{array}{l}\text { reed } \\
2.3\end{array}$ & $\begin{array}{l}\text { fasten } \\
40\end{array}$ & ig. 3.45 & 0.24 & 0.00 & & \\
\hline IV' & $2: 195-$ & 3.0 & 50 & 3.6 & 0.25 & 0.000175 & 0.000633 & 0000045 \\
\hline & & Fasten & down. & & & & & \\
\hline V & 2:34- & 2.8 & 40 & 4.2 & 0.3 & 0.0002 & 0.00084 & \\
\hline$V^{\prime}$ & $2: 545-$ & 2.5 & 40 & 3.75 & 0.27 & 0.0002 & 0.00075 & 0.000054 \\
\hline VI & & 1.5 & $\begin{array}{l}\text { fast } \\
60\end{array}$ & 1.5 & 0.11 & & & 0.000011 \\
\hline $\mathrm{VI}^{\prime}$ & $3: 01 \frac{1}{6}-$ & $1 . S$ & 60 & 1.8 & 0.13 & 0.0001 & 0.00018 & 0.000012 \\
\hline
\end{tabular}

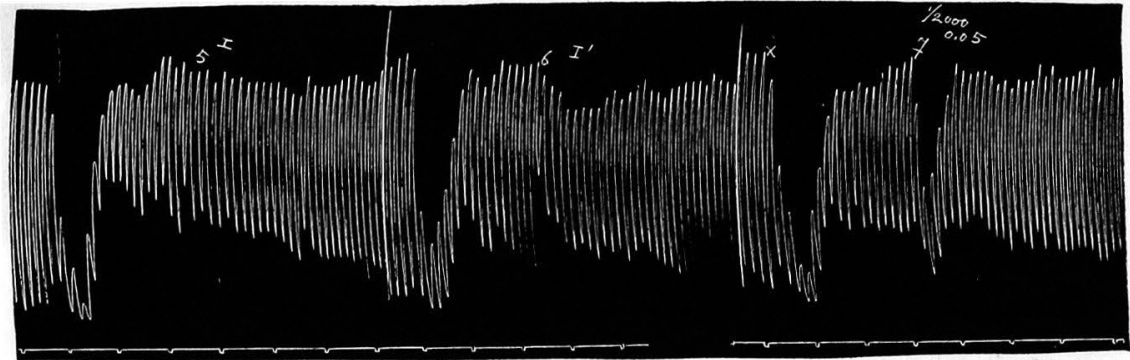

Fig. 1.* a. (Reduced to $\frac{3}{5}$ ). I : Weaker than $I^{\prime}$ and 0.05 c.c. of $1: 2,000,000$. I': A little stronger than or almost as strong as 0.05 c.c. of $1: 2,000,000$.

* In all the intestine tracings, at the mark " $x$ " atropine- Tyrode's solution, in which the rabbit intestine segment was beating rhythmically, was replaced by indifferent blood solution, and at the "numeral" the indifferent blood solution to which a certain quantity of adrenaline chloride of Sankyo \& Co. was added, or by the suprarenal vein blood solution. Quantity of all the bloods employed for one assay was 0.5 c.c.

In all tracings, time intervals 30 seconds.

The number of the suprarenal vein blood specimen solution and the quantity of adrenaline hydrochloride in the adrenaline blood solution are written on every intestine tracing. The former with roman numerals; the latter in c.c. of a given concentration. For example $0.21 / 2000$ means 0.2 c.c. of $1: 2,000,000$ or $0.0001 \mathrm{mgrm}$. 


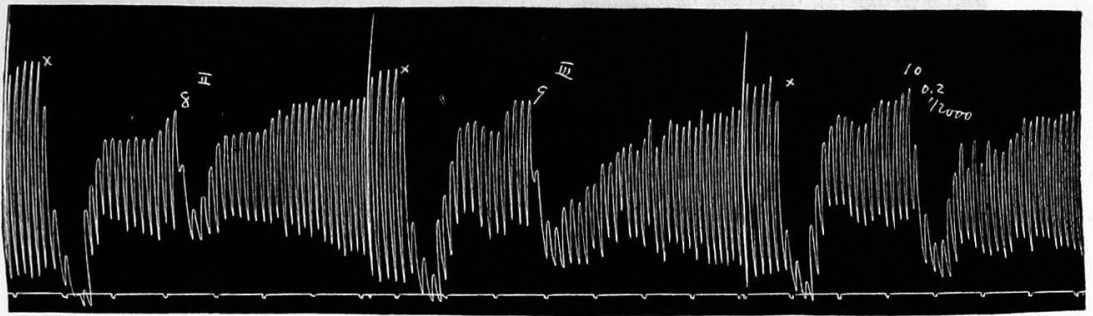

Fig. 1. b. (Reduced to $\frac{3}{5}$ ). II : Weaker than III, stronger than 0.05 c.c. of $1: 2,000,000$. III : Almost as strong as 0.2 c.c. of $1: 2,000,000$.

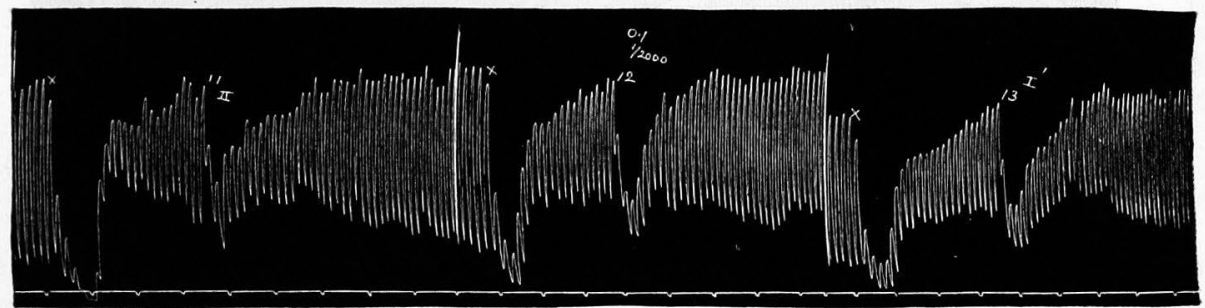

Fig. 1. c. (Reduced to $\frac{3}{5}$ ). II: Weaker than 0.2 c.c. of $1: 2,000,000$ and almost as strong as 0.1 c.c. of $1: 2,000,000$. I': Almost as strong as 0.1 c.c. of $1: 2,000,000$.

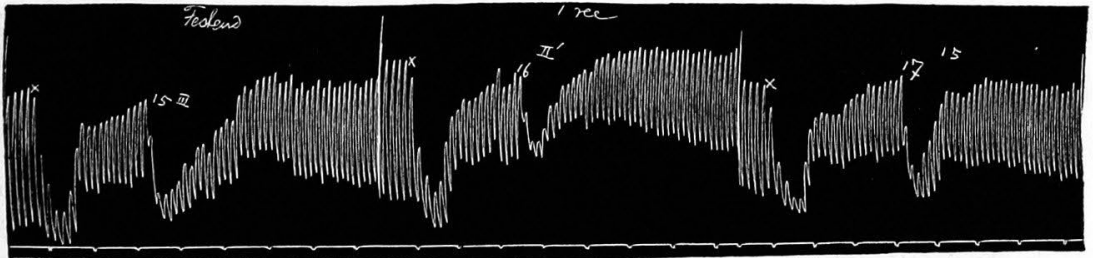

Fig. 1. d. (Reduced to $\frac{1}{2}$ ). III : Decidedly stronger than $\mathrm{II}^{\prime}$; a little stronger than 0.15 c.c. of $1: 2,000,000$; decidedly stronger than $\mathrm{I}^{\prime}$. II': Weaker than 0.15 c.c. of $1: 2,000,000$; almost as strong as $I^{\prime}$.

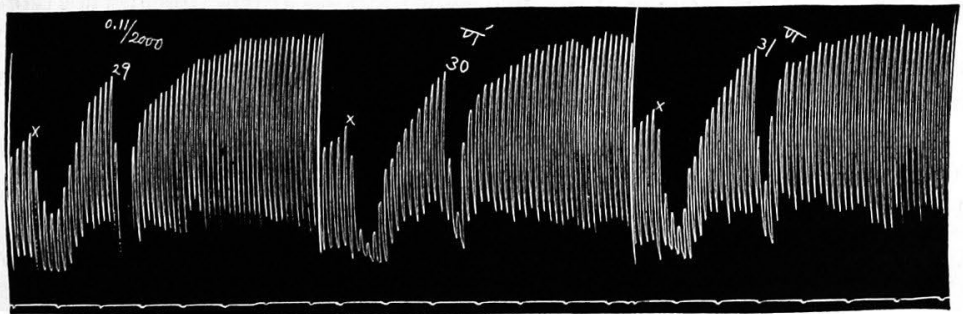

Fig. 1. e. (Reduced to $\frac{3}{5}$ ). VI': Quite the same with VI; almost as strong as 0.1 c.c. of $1: 2,000,000$. (Obs. 29 to 32 ).

(The subsequent tracings from Obs. 29 with new another strip of the same rabbit intestine). 


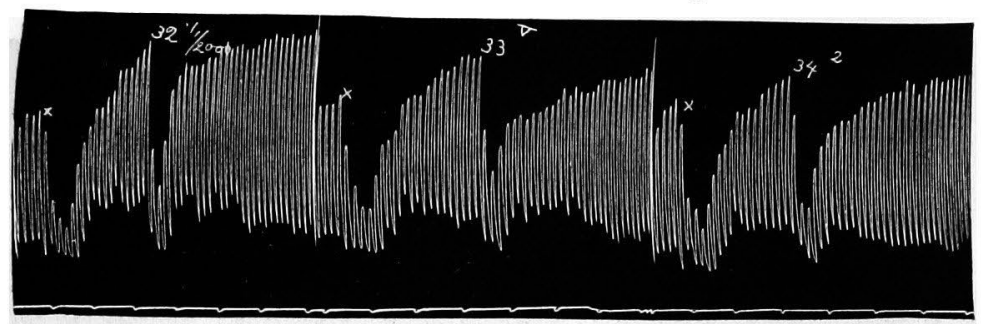

Fig. 1. f. (Reduced to $\frac{3}{5}$ ). V: A little stronger than 0.2 c.c. of $1: 2,000,000$; stronger than 0.1 c.c. of $1: 2,000,000$.

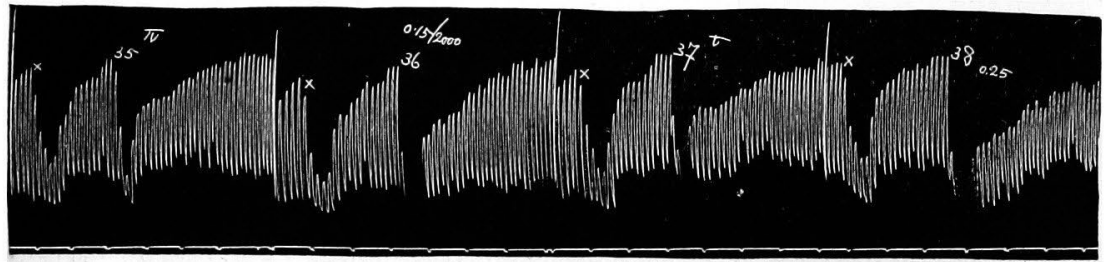

Fig. 1. g. (Reduced to $\frac{1}{2}$ ). IV : Almost as strong as 0.15 c.c. of $1: 2,000,000$; almost as strong as 0.2 c.c. of $1: 2,000,000$. V : Stronger than 0.15 c.c. of $1: 2,000,000$; weaker than 0.25 c.c. of $1: 2,000,000$.

To sum up :

I : Weaker $I^{\prime}$ and than 0.05 c.c. of $1: 2,000,000$. I was taken as a little weaker than $0.00005 \mathrm{mgrm}$. in 1 c.c.

$I^{\prime}$ : A little stronger than or almost as strong as 0.05 c.c. of $1: 2,000,000$; almost as strong as 0.1 c.c. of $1: 2,000,000$. It was assayed at $0.000075 \mathrm{mgrm}$. in 1 c.c.

II : Weaker than III ; stronger than 0.05 c.c. of $1: 2,000,000$; weaker than 0.2 c.c. of $1: 2,000,000$; almost as strong as 0.1 c.c. of $1: 2,000,000$. It was assayed at $0.0001 \mathrm{mgrm}$. in 1 c.c.

II' : Weaker than III ; a little weaker than 0.15 c.c. of $1: 2,000,000$; almost as strong as $I^{\prime}$. It was assayed at $0.000075 \mathrm{mgrm}$. in 1 c.c.

III : Stronger than II'; stronger than II, almost as strong as 0.2 c.c. of $1: 2,000,000$; a little stronger than 0.15 c.c. of $1: 2,000,000$, and by other observations (not reproduced) it was assayed at $0.0002 \mathrm{mgrm}$. in 1 c.c. III': Quite the same with III (tracings not reproduced).

IV : Almost as strong as 0.15 c.c. of $1: 2,000,000$ almost as strong as 0.2 c.c. of $1: 2,000,000$. It was assayed at $0.000175 \mathrm{mgrm}$. in 1 c.c. IV': Quite the same with IV (tracings not reproduced).

V: A little stronger than 0.2 c.c. of $1: 2,000,000$; stronger than 0.1 c.c. of $1: 2,000$, 000 ; stronger than 0.15 c.c. of $1: 2,000,000$; weaker than 0.25 c.c. of $1: 2,000,000$. It was taken as $0.0002 \mathrm{mgrm}$. in 1 c.c. $\mathbf{V}^{\prime}$ : Quite the same with $\mathbf{V}$ (tracings not reproduced).

VI : Quite as strong as VI'; almost as strong as 0.1 c.c. of $1: 2,000,000$ (two assays). It was assayed at "weaker than $0.0001 \mathrm{mgrm}$. in 1 c.c."

The lumbar route operation was performed on the dog, that had completely recovered its body weight 1.5 monates after the dorsal roots operation from the $\mathrm{X}$ thoracic to the II lumbar cord, and appeared quite nor- 


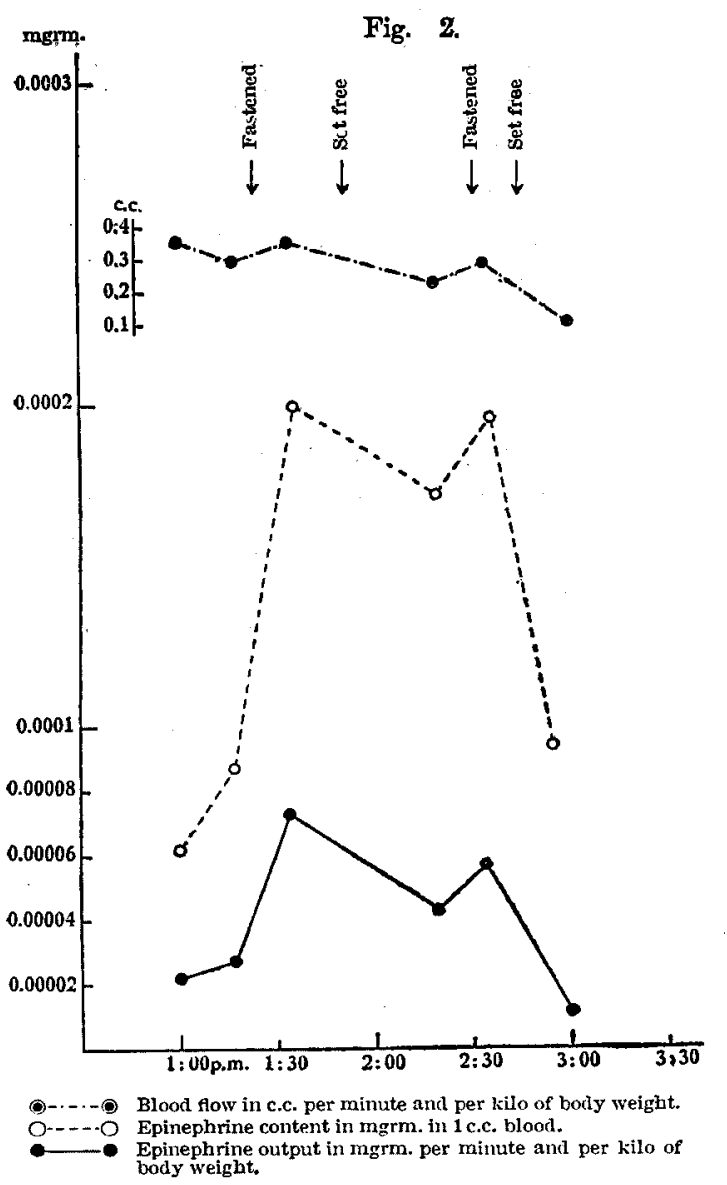

mal save for a trace of paresis in the left hind foot, without evoking any sign of pain. The $\mathrm{dog}$ eagerly ate and drank, as in daily life, meat, cake and milk during the operation. He was standing to begin with, afterwards he sat on his hind legs or on all four limbs. About one hour was allowed to elapse between the operation and the first collections of blood samples. While the first 4 specimens were taken successively the animal was wholly quiescent and appeared as if he noticed nothing happening to himself. After the lapse of some minutes panting respiration took place at once and lasted some minutes; we were not able to note any appreciable cause for it. After subsidence of the panting the animal was fastened down on the table prone which was accompanied by plaintive vocalizations and violent strugglings; some blood samples were collected during this restless interval. The body temperature increased about one degree. Then the $\operatorname{dog}$ was freed from fastening; during the free spell the dog drank milk. Collection of samples was repeated during this rest period and the subsequent fastening period. The last two specimens were taken from the dog freely sleeping on the table. The indifferent blood was shed at the end of the experiment from a muscle branch of a lumbar artery.

Turning now to the results of determinations, the first four samples 
collected in the free period indicated the blood flow rate as $0.3-0.36$ c.c. per kilo and per minute, and the content of epinephrine in 1 c.c. blood as 0.000075 to 0.0001 mgrm., except the I sample which contained less than $0.00005 \mathrm{mgrm}$. in 1 c.c. Accordingly the epinephrine output from the left gland per kilo body weight and per minute was calculated as less than $0.000018 \mathrm{mgrm}$. by the I specimen and $0.000024-0.00003 \mathrm{mgrm}$. in theother three samples. The first fastening doubled the epinephrine concentration of the suprarenal vein blond compared with the above mentioned samples except I specimen, while the rate of blood flow through the gland underwent no alteration practically, consequently the epinephrine output increased from $0.00003 \mathrm{mgrm}$. per kilo and per minute to $0.00007 \mathrm{mgrm}$. In the subsequent rest spell the epinephrine output decreased, but did not yet recover the values in the first rest period. The effect of fastening was again visible in the $\mathrm{V}$ and $\mathrm{V}^{\prime}$ samples taken during the last fastening interval, though somewhat inferior to the first time of fastening. Thus an accelerating effect of the fastening upon the epinephrine discharge was unmistakably demonstrable. Finally a word is due regarding the smallness of the rate of epinephrine liberation witnessed during the sleeping of the animal in the last two specimens. The rate of blood flow as well as the epinephrine content in the blood plainly reduced, with an evident diminution in the rate of epinephrine output as the result.

The results are graphically presented in the accompanying figure. The dash-dot line on the chart indicates the rate of blood flow in c.c. per kilo and per minute, the dash line the epinephrine content in mgrm. in 1 c.c. blood and the solid line the epinephrine output in mgrm. per kilo and per minute. The effect of the fastening down is clearly seen at a glance on the chart.

The results on Dog 7 listed in the table, are worth presenting particularly. The dog was first fastened prone on the table, and the lumbar route preparation was made on the left side. Throughout the fastening and operation the dog cried and struggled very furiously and uninterruptedly ; this extremely excited spell was qualified by an extraordinarily quick liberation of epinephrine that was solely due to the enormously high epinephrine concentration in the blood from the gland. Such a high concentration of epinephrine has been observed only very seldom in this laboratory. Sensory stimulation and asphyxia were capable of introducing a similar concentration in the cava pocket bloods in a few of the animals under narcosis, ${ }^{6}$ )

6) Sakuji Koda m a, Tôhoku J. Exp. Med., 1923, 4, 206 ; 216 ; Ibid., 1924, 5, 63. 
while an intravenous injection of nicotine occasioned an outflow of blood holding a further high concentration of epinephrine through the cava pocket of anaesthetized (ats. ${ }^{7}$ )

At $10: 38.5$ the body temperature was measured as $39.8^{\circ}$ in contrast with $38.5^{\circ}$ at $9: 18$, some minutes after fastening. At $10: 44$ the dog was freed from fastening and at $10: 55$ he ate eagerly some pieces of fish. In parallel with the complete disappearance of the excited state of the animal the emancipation from the fastening induced a considerable lowering of the epinephrine concentration of the suprarenal vein blood. In fact the latter change resulted in a great reduction in the rate of epinephrine output, the velocity of blood current remaining wholly unaltered ; and in reality it became only one hundredth of that in the former excited stage. 'This rate in the rest spell is just the average of the spontaneous liberation of epinephrine from one gland (0.00003-0.00004 mgrm. per kilo and per minute), quoted in the foregoing paper.

At 10:58 the body temperature was measured as having reduced a little $\left(39.4^{\circ}\right)$. Because of coagulation of blood in the lumbal vein which could not be removed despite several trials, the region of the right gland was uncovered, without fastening the dog. This was really our first attempt to carry out the lumbar route operation on the dog freely sitting on the table. Although it was our intention from the beginning to perform the lumbar route operation on the freely sitting or standing dog, we wished to try it first after some more practice on the fastened dogs. The extraordinarily violent reactions of this dog against fastening down making the operation on the left side very difficult, led us to try it earlier than we had expected, and it was really successful.

During the operation on the right side the dog behaved itself quite tranquilly. Collection of some samples in the quiet period was followed by that in the fastening period, during which the dog yelled incessantly and struggled very violently, but only in the same degree as seen ordinarily in other dogs, and by no means so furiously as the first time of fastening. The fastening induced some acceleration in the epinephrine output, but this time it was never excessive; the concentration of XI sample increased nearly double, but the output a little less than double the previous rest stage, the rate of blood current being found a little diminished.

Some tracing indicating these particularly remarkable evidences will be reproduced in the following pages.

7) Tadashi Sugawara, Ibid., 1925, 6, $443 \mathrm{f}$. 
The first two samples, mixed together, taken during the first fastening period, in which the dog was excited uninterruptedly and quite furiously, was found at the first tracings, unexpectedly, to contain epinephrine in a considerable amount, in contrast to the usual findings in the present investigations. The blood specimen I \& II mixed together totally inhibited the rhythmic movements of the intestine segment when applied after diluting with 4 volumes of Ty rode's solution in the usual manner, as illustrated in Fig. 3, a. Further dilutions were tried. Finally when the sample was diluted first with 4 volumes of indifferent blood and then again with 4 volumes of Ty rode's fluid, viz. when diluted 25 times, such an inhibition shown in Fig. 3, f\&g was observed. The blood specimens taken during the remaining various periods were administered to the strip with a dilution in the usual way, yielding an inhibition of intestine movements in a moderate or small degree, as some other tracings reproduced show.

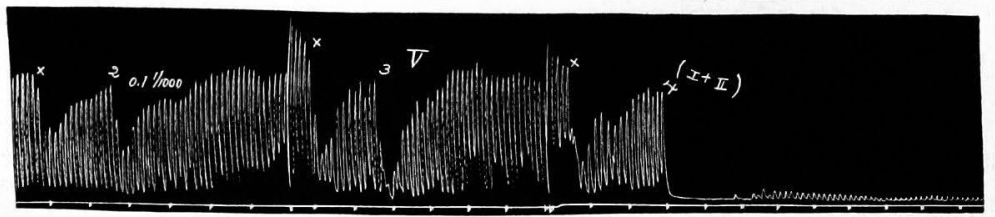

F.g. 3.§ a. (All the tracings are reduced to $\frac{1}{2}$ ) V : Slightly weaker than 0.1 c.c. of 1: 1,000,000. I+II : Almost maximum inhibition.

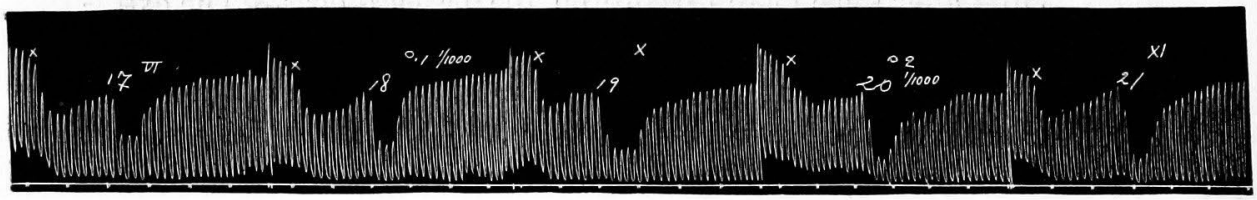

Fig. 3. b. VI : A very little weaker or almost as strong as 0.1 c.c. of $1: 1,000,000$. $\mathrm{X}$ : Stronger than 0.1 c.c. of $1: 1,000,000$; weaker than 0.2 c.c. of $1: 1,000,000$. XI : Weaker than 0.2 c.c. of $1: 1,000,000$; stronger than 0.05 c.c. of $1: 1,000,000$.

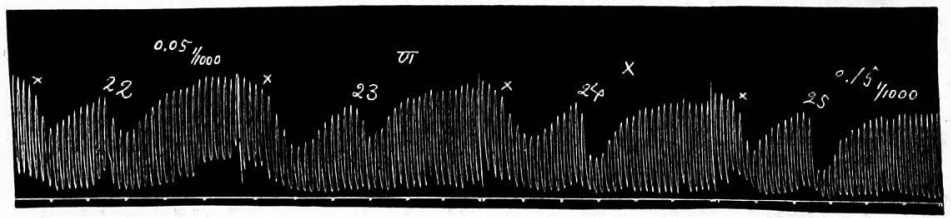

Fig. 3. c. VI: A little stronger than 0.05 c.c. of $1: 1,000,000$. X : Stronger than VI; a little weaker than 0.15 c.c. of $1: 1,000,000$.

$\S$ See the foot-note on p. 12. 


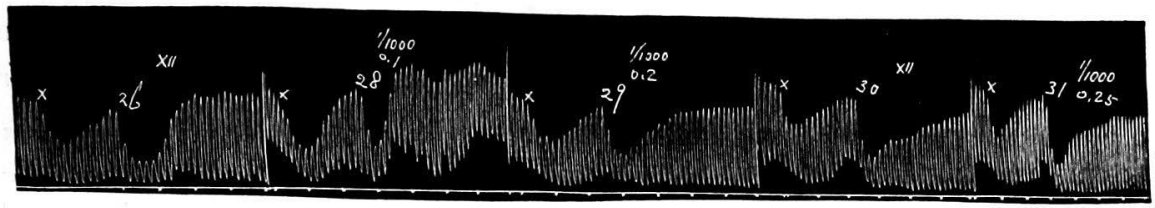

Fig. 3. d. XII : Stronger than 0.15 c.c. of $1: 1,000,000$; stronger than 0.1 c.c. of $1: 1,000,000$; stronger than 0.2 c.c. of $1: 1,000,000$; almost as strong as or a little weaker than 0.25 c.c. of $1: 1,000,000$.

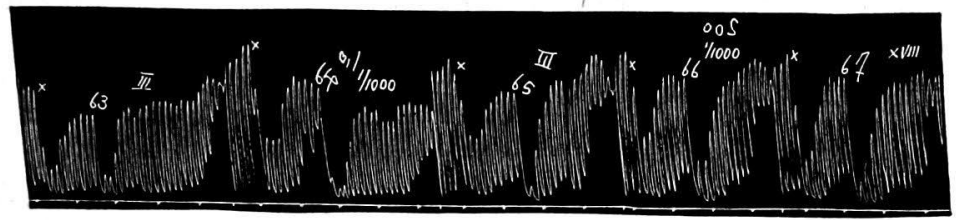

Fig. 3. e. III : Weaker than 0.1 c.c. of $1: 1,000,000$; stronger than 0.05 c.c. of $1: 1,000$ 0 0. XVIII : A little stronger than 0.05 c.c. of $1: 1,000, \mathrm{C00}$.

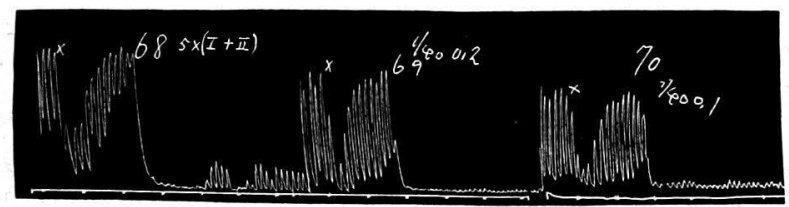

Fig. 3. f. $5 \times(I+I I):$ Weaker than 0.2 c.c. and 0.1 c.c. of $1: 40,000$.

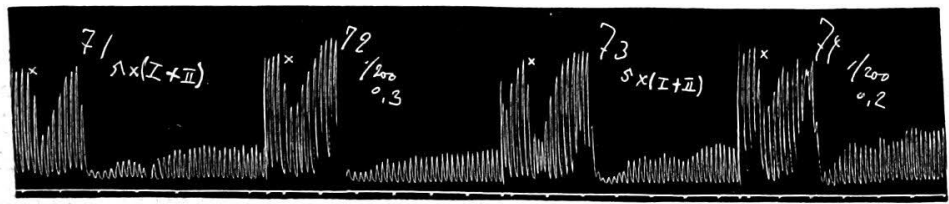

Fig. 3. g. $5 \times(\mathrm{I}+\mathrm{II}):$ Almost as strong as or a little weaker than 0.3 c.c. of $1: 200$, 000 ; stronger than 0.2 c.c. of $1: 200,000$.

The rest of the first specimen (I \& II mixed together) was placed on ice, and the next day it was applied for the study on the stability of epinephrine, which will be published later by one of us (Sugawara).

In dogs 1, 2, 10 and 12 the fastening exerted an augmenting influence upon the epinephrine output, though not so evidently as the above cited examples (Dogs 7 and 8). In 1, 2 and 10 (comparison of IV \& V samples with III and also with VI and VII) the confinement of the animal doubled the epinephrine output. In Dog 12 the concentration and output prior to the fastening were also very small, and the acceleration was small. In these dogs the fastening resulted in whining and struggling. 
An augmenting effect of the fastening upon the epinephrine liberation was definitely missed in. Dogs 3, 4, 5 and 11, and doubtful in Dogs 6, 9 and 13. Dogs 3, 4, 5 and 11 reacted with whining and violent struggling against confinement, whereas Dogs 6, 9 and 13 showed no reaction or only one of a minor degree.

In Dogs 4 and 9 the epinephrine concentration and also the output were very small throughout the whole experimental course.

While the hind limbs of most dogs became more or less paretic after section of the dorsal roots no abnormity was observed in the hind legs of 4 dogs (Dogs $4,10,12 \& 13$ ), that might be taken as token of the complete integrity of the ventral spinal roots. Of the latter set of animals Dogs 4 and 13 portrayed no or only a doubtful acceleration in the discharge of epinephrine in response to the fastening.

From the figures above illustrated, it may be justifiable to take it for granted that the fastening down of dogs is capable of evoking an acceleration in the epine hrine output from the suprarenal gland in about half of the cases. The degree of acceleration by the fastening was also somewhat inferior in comparison with the sensory stimulation. Namely, in potency of eliciting acceleration of the epinephrine liberation the fastening down itself is somewhat subordinate to the latter line of attack.

In $\operatorname{Dog} 7$, which betrayed uninterruptedly extremely violent reactions during the first fastening, including the lumbar route operation, the samples taken twenty minutes after conclusion of operation showed an enormously exaggerated output. That the operation itself should not be taken as responsible for this extraordinary increase can be inferred from the facts that the extremely vigorous reactions were observed incessantly during the fastening and never appeared to be exacerbated by the addition of operative manipulation, and further that the second operation of the same nature on the opposite side, that was carried out in succession, but when the dog was freely sitting on the table, without being restricted, occasioned no sign of pain, anger etc. and correspondingly no excessive output of epinephrine.

This remarkable fact unexpectedly established in Dog 7 could be taken as definite eridence for an acceleration of epinephrine output attendant upon the most violent and long continued excitement of the dng. Though this inference is in fact borne out by only a single experience, we here speak of what we know by experience but not in order to disprove what one or another investigator has spoken.

Speaking on the whole, the behavior of the suprarenal medulla in response to fastening seems to correspond well with the change in the blood sugar level by that manipulation. Contrary to rabbits, dogs respond to the fastening not only not invariably with an increase of the blood sugar level, but also its degree is far less than in the rabbit. ${ }^{8)}$ Since we have rot undertaken, however, a parallel determination of blood sugar content in the present investigations, it must be left unanswered whether or not the augmentation in the epinephrine liberation and the hyperglycaemia are closely associated in each fastening experiment. It is scarcely necessary to add here that if it is found to be so, whether they are

8) Iju. Fujii, Tôholzu J. Exp. Med., 1922, 3, 126. 
causally related or not is open to question, and must be answered by submitting the matter to a special test.

As to the nature of the underlying mechanism whereby the increase in blood sugar concentration is affected by the fastening there still remain different views. According to some writers, as Cann on and Müller, the emotional disturbances attendant upon the fastening must be solely or chiefly accounted the cause of this kind of hyperglycaemia, while Ste wa $\mathrm{r}$ and $R_{0}$ g of $f^{9}$ inclined to assume it as possibly standing on a different footing from the emotional one, the inference being that an increase of the blood sugar content occurred when the animal had been kept for some time on the board, whether or not it had been purposely "frightened," etc. Bang would take, too, some more complicated conditions as responsible for the occurrence of the fisting hyperglycaemia.

As above related the fastening down of dogs is capable of evoling an increase of epinephrine discharge is well established by the present investigations, but in regard to the processes taking place in the organism, which are intermediate between the fastening down itself and the centrum for the epinephrine output, we are at present wholly ignorant.

In this connection we nust remember $\mathrm{Cannon}$ 's view of emotional stimulation of epinephrine liberation. ${ }^{10}$ ) He, with a co-worker, was able to detect an increase of epinephrine content in the inferior cara blood of cats when frightened by confronting them with a barking dog. Cats were fastened on the table, but not generally anaesthetized. Bloods were collected by means of a flexible catheter and epinephrine was assayed by means of the cat's intestine strip. In one cat they detected an intensively inhibiting power in the bloods which increased further with the lasting of the excitement such as eleven minutes to fifteen. In other instances the epinephrine content in the inferior cava blood taken in the excited stage was far inferior to those from this cat.

Some years later Stew art and Rog of $f^{9}$ ) (p. $573 \mathrm{ff}$.) failed to duplicate the findings of the Boston physiologist, the same procedure being applied for collection of blood specimens in the inferior cava vein anterior to the entrances of bloods from the suprarenal bodies.

More recently $\mathrm{Hartman}$ and his associates ${ }^{11)}$ were not so successful in adhering to the view introduced by Cannon. Cats with the completely denervated eye came into application. A small excitable dog was brought in front of the cat which was fastened in a comfortable animal holder or else the legs and body wrapped in a sack and beld, with the head free. These cats were relatively calm and at the same time the pupil dilation failed to occur or was only small.

Recently Cannon, with his co-adjutor, reported that the denervated heart in starving cats beat with an increased rate during the breaking out of pseudaffective phenomena, while the removal of the suprarenal bodies reduced this acceleration largely. ${ }^{12}$ )

In regard to this highly interesting and important question at issue we have not yet available evidence in our own hands to support one view or the other, except a single experience on Dog 7. In order to get a more clear, definite view about this matter we hope to have some other opportunities in making such a experiment as on Dog 7. Only in this connection we may add here some experiences made in trying to bring dogs into an ex-

9) G. N. Stewart and J. M. Rog off. Am. J. Physiol., 1917, 44, 572.

10) W. B. Cannon and D. de la Paz, Ibid., 1911, 28, 64.

11) F. A. Hartman, H. A. M cCordock and M. M. Loder, Am. J. Physiol., $19 \pm 3,64,5 \mathrm{ff}$.

12) W. B. Cannon and S. W. Briton, Am. J. Physiol., 1925, 72, 283. 
cited state, by fronting, for example, with a cat, but not by such a manipulation as fastening down, sensory stimulation. Briefly stated, our trials were however unsuccessful ; we have been left with a strong impression that it is quite difficult in our usual laboratory conditions to induce a serious fight between a dog and a cat or two male dogs as is commonly seen in their natural state. Such experimental conditions, as placing the dogs on the tables in a laboratory room, the standing of a certain number of experimentors and assistants around the animals would interfere disastrously with the breaking out of angry fighting by confronting the dog with the cat, etc. Fastening of the animal on the table or wrapping it in a sack, etc. may also necessarily modify in some way emotional disturbances which night be induced by confronting an opponent.

A lively young, tame dog was once fastened on the table supine, but the dog was still so cheerful as to look round and wag his tail. When a furious cat in a wire cage was at once brought before him, the dog neither yelled nor struggled, but became apparently wholly tranquill. This approach of the cat called forth in the dog a definite increase of the blood sugar percentage. On the other hand there were dogs which yelled and struggled on confronting a cat in a wire cage, but did not indicate any augmentation of blood sugar content. Similar experiences were previously noted by Bang on rabbits. ${ }^{13)}$ Although it is indubitably to put the cart before the horse to make the deduction whether or not the animal is excited from the behavior of the blood sugar level, the emotional state of the animal must be certainly interpreted with great care, and especially when the animal is confined in an unnatural state. Of the above related young dog we had in fact the impression that it might probably have been feeling fear in spite of its entire tranquility.

And further, when we shall be successful in haring cases in which the animal can react in the usual laboratory conditions to an attack by its enemy in a quite natural manner, we may meet with difficulty in securing the blood samples from the suprarenal gland, measuring the pupil diameter, etc. with safety to the experimentors and without interfering with the fight itself.

When the dog on a table, as in the present investigations, was confronted by a cat enclosed in a wire cage, commonly it showed more or less symptoms of fear, the teeth being bared, the head turned aside from the opponent, sometimes plaintive vocalizations being uttered. Such an excited state lasted usually only more or less transitorily. In our few experiences furious rage was not observed.

At all events it is of importance to notice in the present researches that all the dogs which were qualified with an augmented epinephrine liberation expressed violent reactions, as crying and struggling, in response to the fastening, while half of those which did not betray any or only small sign of accelerated epinephrine output behaved themselves quite indifferently to the same manipulation, and further, especially that an enormous acceleration in the output was discovered in Dog 7 when it was extraordinarily excited during the first fastening.

\section{II.}

The results of sensory stimulation experiments will now be considered.

While we failed to perceive an accelerating influence of sensory stimulation upon the epinephrine output from suprarenals by practising the

13) I. Bang, Hop pe-Se y ler's Ztschr., 1913, 88, 45. 
cava pocket method on anaesthetized cats and dogs in half of the instances, we were able to recognize it in every non-anaesthetized dog by the same method and in the great majority of stimulations. The de-afferentation of the operation field obviates the necessity of narcosis; narcosis acts as inhibiting the reflex output of epinephrine. ${ }^{\text {14) }}$

Now further trials were made, in working with non-anaesthetized dogs, in order to see whether or not by utilizing the lumbar route preparation entirely corroborating results with those yielded by the cava pocket method could be obtained in regard to the sensory effect. This study is the more significant in that the new method conveys an initial output (spontaneous liberation) of the magnitude of a different low order compared with the cava pocket method.

The new data are epitomized in the table above given, and the protocolls originating from Dog 13 are reproduced fully.

In order to show the results of sensory experimentation at a glance, a chart corresponding to the data on Dog 13 carried out January 28 last year is given, the lettering bcing the same as noted in Fig. 2 belonging to the fastening experiment. For the sake of showing readily the effect of stimuli, the time during the stimulation experiments in proper sense is taken as especially exaggerated, as in the manner explained in the legend.

Sensory stimulation was carried out on the dogs necessarily fastened prone on the table.

In some $\operatorname{dogs}$ the median nerve (on the right side) was laid bare, ligated and cut with the central end prepared for stimulation, but later the great auricular nerve was preferred. The induction shock used for stimulation was usually barely perceptible to the tongue at $15 \mathrm{cms}$. coil distance. Sensory stimulation was followed by very violent, aggressive reactions. During the stimulation the head of the dog was firmly fixed by a technical assistant sitting before the dog holding the ears with his hands, otherwise the dog would instantaneously direct its mouth furiously towards the hands of the experimentor causing stimulation. 'The stimulation was also immediately followed by a remarkable deepening of breathing and powerful movements of the limbs even in so confined a position, both of which would interfere very seriously with collection of blood samples. The kidney inclined to get rid of the lumbar incision. The difficulties were

14) Sakuji Kodama, Tòhoku J. Exp. Med., 1923, 4, 166; 1924, 4, 465; 1924, 4, $601 ; 1924,5,149 \& 157$; J. Biophysics, $19(23-) 24(-26), 1,79$; Tadashi Sug a wa ra, Masa. W at a n a bé and Shidzuka Sa ito, Tôhoku J. Exp. Med., 1926, 7, 1. 


\section{Example II.}

$\operatorname{Dog} 13$. 우.

19. XII. 1925. 20 kilos. $\mathrm{L}_{3}-\mathrm{D}_{10}$ dorsal spinal roots severed. 13. I. 1926. 21.5 kilos. Experimented on effect of sensory stimulation and fastening upon the epinephrine output from left suprarenal gland. Hind legs normal.

28. I. 1926. 21.5 kilos. Same kind experiments, the right suprarenal gland being employed.

\begin{tabular}{|c|c|c|c|c|c|}
\hline Date & 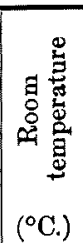 & 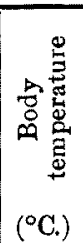 & 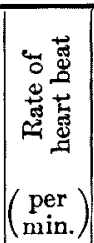 & 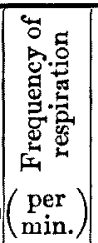 & Experimental process and others \\
\hline
\end{tabular}

13. I. 1926.

\begin{tabular}{|c|c|c|c|c|c|}
\hline $\begin{array}{l}\text { 10:26 A.M. } \\
10: 40-11: 35\end{array}$ & $\begin{array}{l}15 \\
20\end{array}$ & 38.1 & $\begin{array}{l}120 \\
120\end{array}$ & $\begin{array}{l}24 \\
42\end{array}$ & $\begin{array}{l}\text { Completed the operation, with a long string } \\
\text { around central end and a cannula into peri- } \\
\text { pberal end of left lumbosuprarenal vein with- } \\
\text { out tying the animal. }\end{array}$ \\
\hline $\begin{array}{l}11: 35 \\
0: 30 \text { P.M. } \\
0: 35\end{array}$ & 23 & 38.1 & 121 & 42 & $\begin{array}{l}\text { Milk given. } \\
\text { Collected suprarenal vein blood specimen } \\
\text { and } I^{\prime} \text {. }\end{array}$ \\
\hline $\begin{array}{l}0: 40 \\
0: 47\end{array}$ & 24 & 38.2 & 120 & 54 & $\begin{array}{l}\text { Fastend down; no reactions against tying; } \\
\text { dog very calm. }\end{array}$ \\
\hline $0: 49$ & & & & & $\begin{array}{l}\text { Collected suprarenal vein blood specimen } \\
\text { II and II'. Dog very quiet, no crying, no } \\
\text { struggling. }\end{array}$ \\
\hline $\begin{array}{l}0: 55 \\
1: 03-1: 07\end{array}$ & 25 & 38.1 & 114 & 42 & $\begin{array}{l}\text { Prepared n. auricularis mag. dexter, ligat- } \\
\text { ed and cut off. Dog cried, struggled and mic- } \\
\text { turition. }\end{array}$ \\
\hline $\begin{array}{l}1: 22 \\
1: 33\end{array}$ & 25 & 38.3 & 90 & 30 & $\begin{array}{l}\text { Milk given. } \\
\text { Collected suprarenal vein blood specimens } \\
\text { III-VII successively, with and without stimu- } \\
\text { lation of auricular nerve. }\end{array}$ \\
\hline $\begin{array}{l}1: 42 \\
2: 05\end{array}$ & 25 & 38.5 & 72 & 108 & $\begin{array}{l}\text { Milk drunk, dog cried incessantly. } \\
\text { Collected suprarenal vein blood specimens } \\
\text { VIII-XII' successively, with and without stimu- } \\
\text { lation of auricular nerve. Dog cried. }\end{array}$ \\
\hline $\begin{array}{l}2: 15 \\
2: 20\end{array}$ & 23.5 & 38.7 & 120 & 114 & $\begin{array}{l}\text { Collected some indifferent blood from a } \\
\text { muscle branch of a. lumalis. }\end{array}$ \\
\hline 2:30 & & & & & $\begin{array}{l}\text { Sewed up the lumbar incision under asep- } \\
\text { tic precautions }\end{array}$ \\
\hline
\end{tabular}




\begin{tabular}{|c|c|c|c|c|c|}
\hline Time & 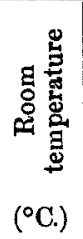 & 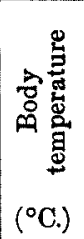 & 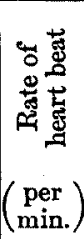 & 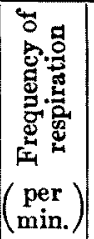 & Experimental process and others \\
\hline
\end{tabular}

28. I. 1926 .

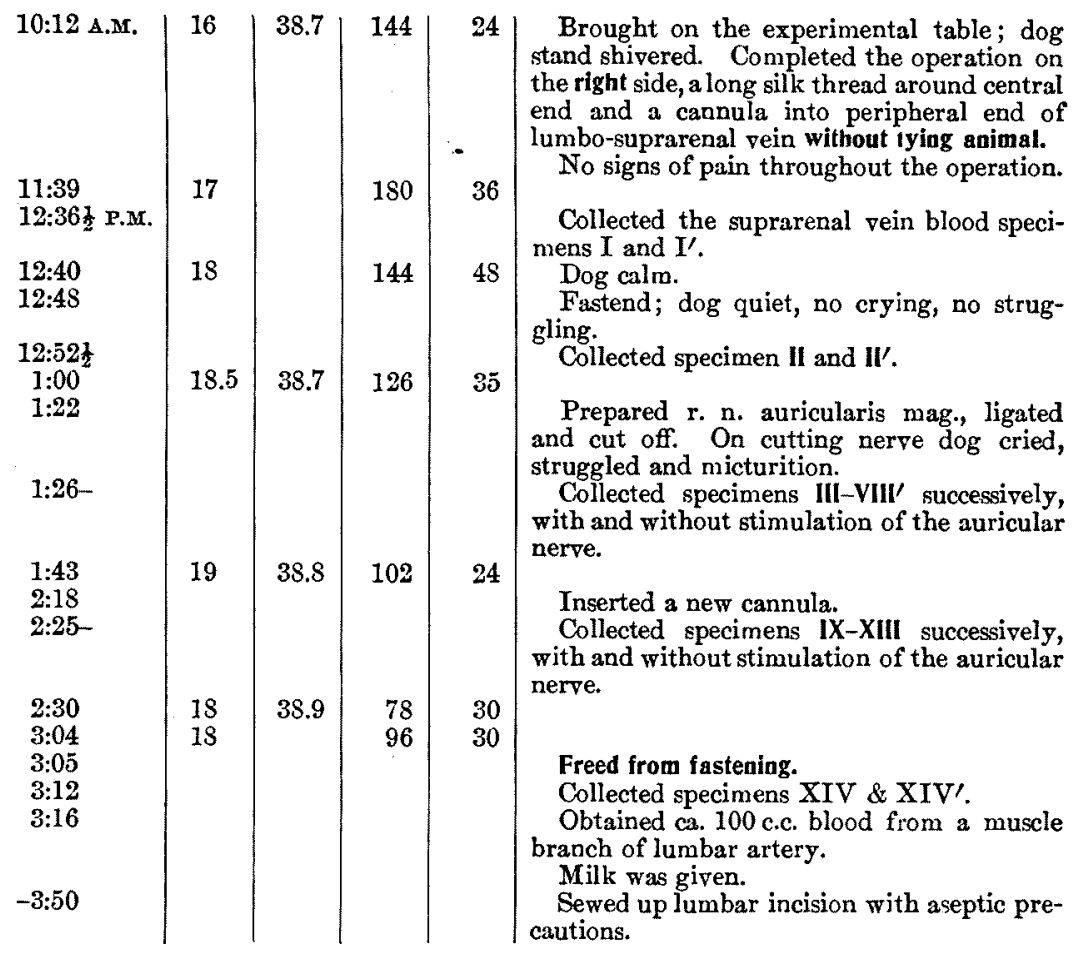

Blood flow, Epinephrine content as well as the epinephrine output were as follows :

\begin{tabular}{|c|c|c|c|c|c|c|c|c|}
\hline \multirow{3}{*}{$\begin{array}{l}\text { No. } \\
\text { of } \\
\text { speci- } \\
\text { men }\end{array}$} & \multirow{3}{*}{$\begin{array}{c}\text { Time } \\
\text { of } \\
\text { collection }\end{array}$} & \multicolumn{4}{|c|}{ Blood flow (c.c.) } & \multicolumn{3}{|c|}{ Epinephrine output (mgrm.) } \\
\hline & & \multirow{2}{*}{ Quantity } & \multirow{2}{*}{$\begin{array}{c}\text { Duration } \\
\text { of } \\
\text { collection } \\
\text { (sec.) }\end{array}$} & \multicolumn{2}{|c|}{ Quantity per min. } & \multirow{2}{*}{$\begin{array}{l}\text { Quantity } \\
\text { contained } \\
\text { in } 1 \text { c.c. }\end{array}$} & \multicolumn{2}{|c|}{ Output per min. } \\
\hline & & & & $\underset{\text { animal }}{\text { per }}$ & $\begin{array}{l}\text { per } \\
\text { kilo }\end{array}$ & & $\underset{\text { animal }}{\text { per }}$ & $\begin{array}{l}\text { per } \\
\text { kilo }\end{array}$ \\
\hline
\end{tabular}

13. I. 1926. Observations on left suprarenal gland.

\begin{tabular}{l|l|l|l|l|l|l|l|l}
$\mathrm{I}$ & $0: 35$ P.M. & 2.3 & 30 & 4.6 & 0.21 & 0.00005 & 0.00023 & 0.000011 \\
$\mathbf{I}^{\prime}$ & $0: 364^{-}$ & 2.4 & 30 & 4.8 & 0.22 & 0.00005 & 0.00024 & 0.000011
\end{tabular}




\begin{tabular}{|c|c|c|c|c|c|c|c|c|}
\hline \multirow{3}{*}{$\begin{array}{l}\text { No. } \\
\text { of } \\
\text { speci- } \\
\text { men }\end{array}$} & \multirow{3}{*}{$\begin{array}{c}\text { Time } \\
\text { of } \\
\text { collection }\end{array}$} & \multicolumn{4}{|c|}{ Blood flow (c.c.) } & \multicolumn{3}{|c|}{ Epinephrine output (mgrm.) } \\
\hline & & \multirow[b]{2}{*}{ Quantity } & \multirow{2}{*}{$\begin{array}{c}\text { Duration } \\
\text { of } \\
\text { collection } \\
\text { (sec.) }\end{array}$} & \multicolumn{2}{|c|}{ Quantity per min. } & \multirow{2}{*}{$\begin{array}{c}\text { Quantity } \\
\text { contained } \\
\text { in } 1 \text { c.c. }\end{array}$} & \multicolumn{2}{|c|}{ Output per min. } \\
\hline & & & & $\underset{\text { animal }}{\text { per }}$ & $\begin{array}{l}\text { per } \\
\text { kilo }\end{array}$ & & $\underset{\text { animal }}{\text { per }}$ & $\begin{array}{l}\text { per } \\
\text { kilo }\end{array}$ \\
\hline
\end{tabular}

Specimens $I$ and $I^{\prime}$ were collected without fastening.

\begin{tabular}{l|l|l|l|l|l|l|l|l} 
II & $0: 49-$ & 2.1 & 30 & 4.2 & 0.19 & 0.00005 & 0.00021 & 0.00001 \\
II' & $0: 50 \frac{2}{3}$ & 3.0 & 30 & 6.0 & 0.28 & 0.00005 & 0.0003 & 0.000014
\end{tabular}

Specimens II and II' were collected under fastening. No reactions upon fastening.

\begin{tabular}{|c|c|c|c|c|c|c|c|c|}
\hline III & $1: 33-$ & 3.1 & 30 & 6.2 & 0.29 & 0.0002 & 0.00124 & 0.000058 \\
\hline V & 1:33\% & 2.4 & 30 & 4.8 & 0.22 & 0.00055 & 0.00264 & 0.000123 \\
\hline & $1: 35 \frac{1}{6}-$ & 3.3 & 30 & 6.6 & 0.31 & 0.0003 & 0.00198 & 0.000092 \\
\hline & $1: 35 \frac{5}{6}$ & 2.8 & 30 & 5. & 0.26 & 0.0004 & 0,00224 & 0.000104 \\
\hline & $-1: 3$ & 3.2 & 30 & 6.4 & 0.29 & 0.0002 & 0.00128 & 0.00005 \\
\hline
\end{tabular}

During the whole period of collection of IV and VI r. n. auricul. mag. stimulated. Coils $9.5 \mathrm{cms}$. at IV and $9.0 \mathrm{cms}$. at VI apart. Reactions to stimulation violent : Crying, struggling and faster respiration.

\begin{tabular}{l|l|l|l|l|l|l|l|l|} 
VIII & $2: 5-$ & 3.0 & 30 & 6.0 & 0.28 & 0.00015 & $\mathbf{0 . 0 0 0 9}$ & 0.000042 \\
IX & $2: 53$ & 1.8 & 30 & 3.6 & $\mathbf{0 . 1 7}$ & $\mathbf{0 . 0 0 0 4}$ & $\mathbf{0 . 0 0 1 4 4}$ & $\mathbf{0 . 0 0 0 0 6 7}$ \\
X & $2: 6 \frac{2}{3}$ & 2.1 & 30 & 4.2 & 0.19 & 0.0001 & 0.00042 & 0.000019 \\
XI & $2: 7 \frac{1}{3}$ & $\mathbf{2 . 2}$ & $\mathbf{3 0}$ & $\mathbf{4 . 4}$ & $\mathbf{0 . 2}$ & $\mathbf{0 . 0 0 0 4}$ & $\mathbf{0 . 0 0 1 7 6}$ & $\mathbf{0 . 0 0 0 0 8 2}$ \\
XII & $2: 8 \frac{1}{3}$ & 1.9 & 30 & 3.8 & 0.18 & $\mathbf{0 . 0 0 0 1 5}$ & 0.00057 & 0.000026 \\
XII' & $2: 10 \frac{1}{2}-$ & $\mathbf{2 . 1}$ & 30 & 4.2 & 0.19 & $\mathbf{0 . 0 0 0 2}$ & 0.00084 & 0.000039
\end{tabular}

During the whole period of collection of IX and XI r. n. auricul. mag. stimulated. Coil distances : $9 \mathrm{cms}$. at $\mathbf{I X}$ and $8.5 \mathrm{cms}$. at XI. Reactions to stimulation marked : Crying, struggling and faster respiration, but somewhat weaker than the first series of stimulation experiment. 10 seconds before and 60 or 30 seconds after the collection of the stimulation samples the suprarenal vein blood were discarded.

28. I. 1926. Observations on right suprarenal gland.

$$
\begin{array}{l|c|c|c|c|c|c|c|c}
\mathrm{I} & 12: 36- & 3.0 & 30 & 6.0 & 0.28 & \overline{0.00005} & \overline{0.00028} & 0.000013
\end{array}
$$

Specimens $\mathrm{I}$ and $\mathrm{I}^{\prime}$ were collected without fastening.

\begin{tabular}{l|c|c|c|c|c|c|c|c} 
II & $12: 51-$ & 2.7 & 30 & 5.4 & 0.25 & $\overline{1}$ & \\
II' & $-12: 52$ & 2.8 & 30 & 5.6 & 0.26 & 0.0001 & 0.00056 & 0.000026 \\
III & $1: 26-$ & 2.8 & 30 & 5.6 & 0.26 & & \\
III' & $-1: 27$ & 2.6 & 30 & 5.2 & 0.24 & 0.000075 & 0.00039 & 0.000018
\end{tabular}

Specimens II, II', III and III' were collected under fastening.

\begin{tabular}{|c|c|c|c|c|c|c|c|c|}
\hline IV & $1: 34$ & 2.2 & 30 & 4.4 & 0.20 & 0.000075 & 0.00033 & 0.000015 \\
\hline V & $1: 34$ & 2.0 & 30 & 4.0 & 0.18 & 0.00025 & 0.001 & 0.000046 \\
\hline VI & $1: 35 \frac{1}{2}-$ & 2.8 & 30 & 5.6 & 0.26 & 0.0001 & 0.00056 & 0.00002 \\
\hline VIII & $1: 36 \frac{1}{6}$ & 2.1 & 30 & 4.2 & 0.19 & 0.00025 & 0.00105 & 0.0000 \\
\hline VIII & $1: 37 \frac{1}{6}-$ & 2.1 & 30 & 4.2 & 0.19 & 0.00015 & 0.00063 & 0.00002 \\
\hline VIII' & $1: 37_{\mathrm{a}-}^{5}-$ & 2.2 & 30 & 4.4 & 0.20 & 0.00015 & 0.00066 & 0.00003 \\
\hline
\end{tabular}

During the whole period of collection of $\mathrm{V}$ and VII $r$. $n$. auricul. mag. stimulated. Coil distance: $10 \mathrm{cms}$. at $\mathrm{V} ; 9.5 \mathrm{cms}$. at VII. Reactions to stimulation violent. 20 seconds after $V, 30$ seconds after VII and 10 seconds in other intervals of 2 specimens the suprarenal vein blood were difcarded.

\begin{tabular}{l|l|l|l|l|l|l|l|l|l}
$\mathbf{I X}$ & $2: 25-$ & $\mathbf{2 . 4}$ & 30 & 4.8 & $\mathbf{0 . 2 2}$ & 0.000075 & 0.00036 & 0.000016 \\
$\mathbf{X}$ & $2: 252-$ & $\mathbf{1 . 0}$ & $\mathbf{3 0}$ & $\mathbf{2 . 0}$ & $\mathbf{0 . 0 9}$ & $\mathbf{0 . 0 0 0 5 5}$ & $\mathbf{0 . 0 0 1 1}$ & $\mathbf{0 . 0 0 0 0 5}$ \\
$\mathbf{X I}$ & $2: 27-$ & 2.0 & 30 & 4.0 & 0.18 & 0.000175 & 0.0007 & 0.000032 \\
$\mathbf{X I I}$ & $2: 28-$ & $\mathbf{1 . 7}$ & $\mathbf{3 0}$ & $\mathbf{3 . 4}$ & $\mathbf{0 . 1 5}$ & $\mathbf{0 . 0 0 0 3 5}$ & $\mathbf{0 . 0 0 1 1 9}$ & $\mathbf{0 . 0 0 0 0 5 5}$ \\
$\mathbf{X I I I}$ & $\mathbf{2 : 2 9 -}$ & $\mathbf{2 . 5}$ & $\mathbf{3 0}$ & $\mathbf{5 . 0}$ & $\mathbf{0 . 2 2}$ & $\mathbf{0 . 0 0 0 1 5}$ & 0.00075 & $\mathbf{0 . 0 0 0 0 3 4}$
\end{tabular}

During the whole period of collection of $X$ and XII r. $n$. auricul. mag. stimulated. Coil distance : $9 \mathrm{cms}$. at $X ; 8.5 \mathrm{cms}$. at XIl. Reactions to stimulation marked, but 


\begin{tabular}{|c|c|c|c|c|c|c|c|c|}
\hline \multirow{3}{*}{$\begin{array}{l}\text { No. } \\
\text { of } \\
\text { speci- } \\
\text { men }\end{array}$} & \multirow{3}{*}{$\begin{array}{c}\text { Time } \\
\text { of } \\
\text { collection }\end{array}$} & \multicolumn{4}{|c|}{ Blood flow (c.c.) } & \multicolumn{3}{|c|}{ Epinephrine output (mgrm.) } \\
\hline & & \multirow{2}{*}{ Quantity } & \multirow{2}{*}{$\begin{array}{c}\text { Duration } \\
\text { of } \\
\text { collection } \\
\text { (sec.) }\end{array}$} & \multicolumn{2}{|c|}{ Quantity per min. } & \multirow{2}{*}{$\begin{array}{l}\text { Quantity } \\
\text { contained } \\
\text { in } 1 \text { c.c. }\end{array}$} & \multicolumn{2}{|c|}{ Output per min. } \\
\hline & & & & $\begin{array}{c}\text { per } \\
\text { animal }\end{array}$ & $\begin{array}{l}\text { per } \\
\text { kilo }\end{array}$ & & $\begin{array}{c}\text { per } \\
\text { animal }\end{array}$ & $\begin{array}{r}\text { per } \\
\text { kilo }\end{array}$ \\
\hline
\end{tabular}

somewhat weaker than before. At $\mathbf{X}$ dog urinated with struggling. 60 seconds after $\mathbf{X}$, 30 seconds after XII and 10 seconds in other interval of two specimens the suprarenal vein blood were discarded.

\begin{tabular}{l|l|l|l|l|l|l|l|l} 
XIV & $3: 12-$ & 3.1 & 30 & 6.2 & 0.29 & 0.000075 & 0.000465 & 0.000021 \\
XIV' & $3: 12 \frac{2}{3}$ & 3.0 & 30 & 6.0 & 0.28 & 0.000075 & 0.00045 & 0.000020
\end{tabular}

$\mathrm{XIV}$ and XIV': After freed from fastening.

13. I. 1926 .

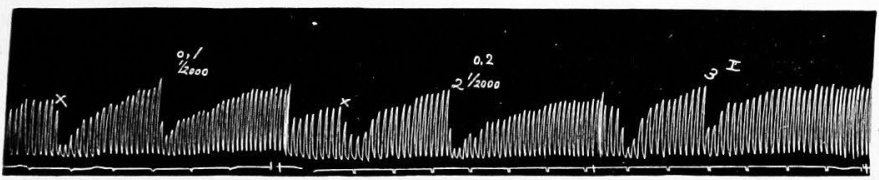

Fig. 4. (All the tracings are reduced to $\left.\frac{1}{2}\right) \S$ a. I: Weaker than 0.2 c.c. of $1: 2,000,000$ and 0.1 c.c. of $1: 2,000,000$; aln:ost as strong as 0.05 c.c. of $1: 2,000,000$ (Obs. 4).

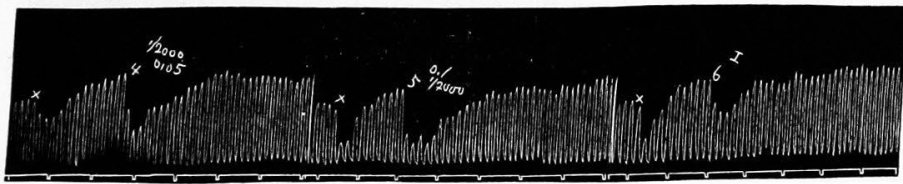

Fig. 4. b. I: Weaker than 0.1 c.c. of $1: 2,000,000$; quite as strong as $I^{\prime}$.

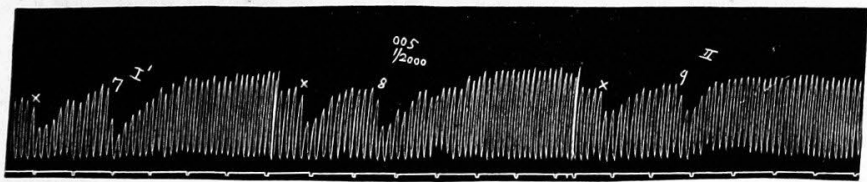

Fig. 4. c. II : Almost as strong as 0.05 c.c. of $1: 2,000,000$; almost as strong as II'. $I^{\prime}$ : Almost as strong as 0.05 c.c. of $1: 2,000,000$.

$\S$ See the foot-note on p. 12. The quantities of the suprarenal vein blood specimens and the indifferent blood in the adrenaline blood solutions used for one tracing were always 0.5 c.c. 


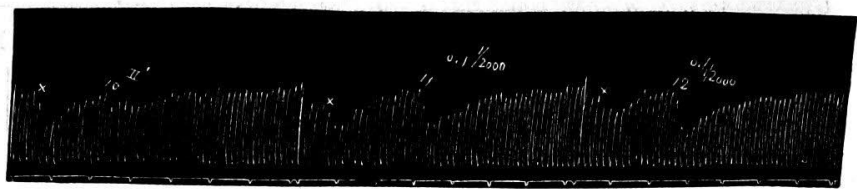

Fig. 4. d. II' : A little weaker than 0.1 c.c. of $1: 2,000,000$; almost as strong as II.

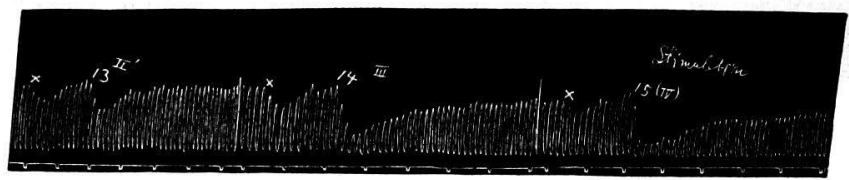

Fig. 4. e. $\mathrm{II}^{\prime}<\mathrm{III}<\mathrm{IV}>\mathrm{V}$ (Obs. 16). $\mathrm{II}^{\prime}:$ Almost as strong as 0.1 c.c. of $1: 2,000$, 000.

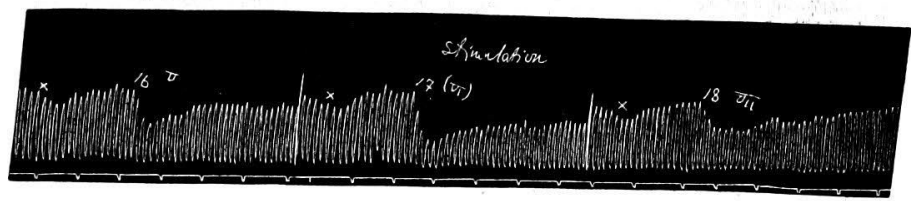

Fig. 4. f. $\mathrm{V}<\mathrm{VI}>\mathrm{VII}<\mathrm{XII}$.

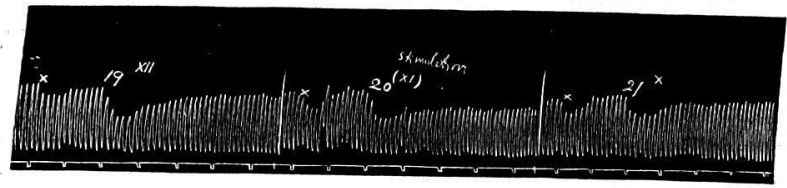

Fig. 4. g. $\quad \mathrm{XII}<\mathrm{XI}>\mathrm{X}<\mathrm{IX}$.

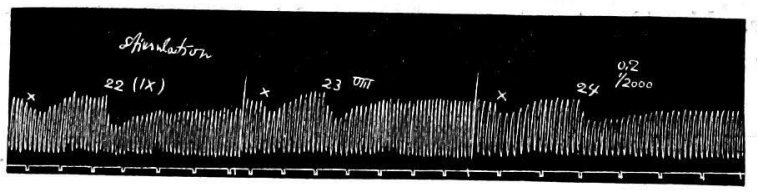

Fig. 4. h. IX: Stronger than VIII. VIII : Weaker than 0.2 c.c. of $1: 2,000,000$. 


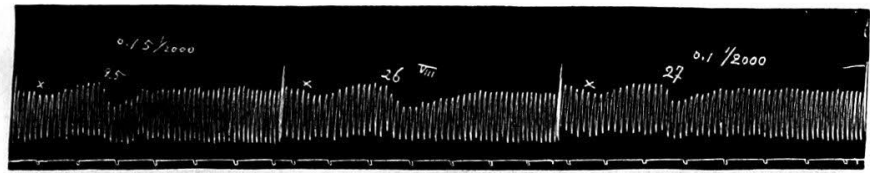

Fig. 4. i. VIII : Almost as strong as 0.15 c.c. of $1: 2,000,000$; stronger than 0.1 c.c. $1: 2,000,000$.

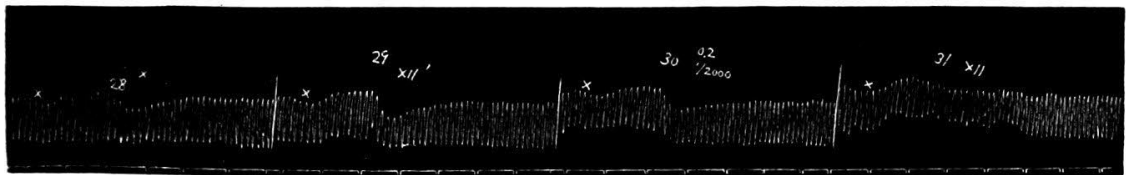

Fig. 4. j. $\mathrm{X}$ : Almost as strong as 0.1 c.c. of $1: 2,000,000$. XII': Almost as strong as 0.2 c.c. of $1: 2,000,000$; a little stronger than $X$. XII : Weaker than 0.2 c.c. of $1: 2,000$,000 .

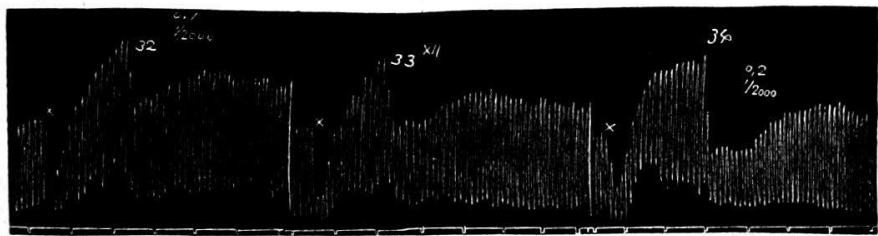

Fig. 4. k. XII : Stronger than 0.1 c.c. of $1: 2,000,000$; weaker than 0.2 c.c. of $1: 2,000$,000 .

(From Obs. 32 another intestine strip of the same rabbit was employed).

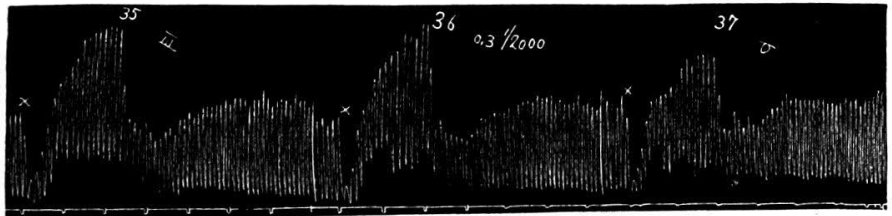

F g. 4. l. III : Almost as strong as 0.2 c.c. of $1: 2,000,000$; weaker than 0.3 c.c. of $1: 2,000,000$. V : Almost as strong as or a very little stronger than 0.3 c.c. of $1: 2,000,000$; stronger than 0.2 c.c. of $1: 2,000,000$.

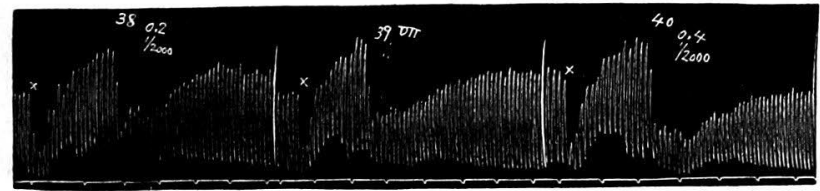

Fig. 4. m. VII : Almost as strong as 0.2 c.c. of $1: 2,000,000$; weaker than 0.4 c.c. of $1: 2,000,000$. 


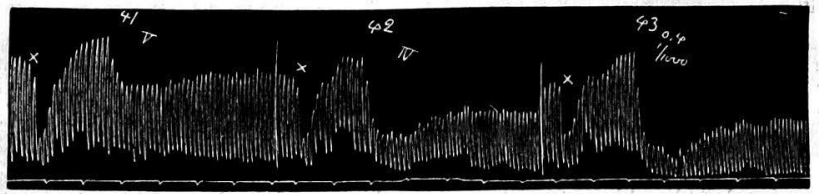

Fig. 4. n. V: Far weaker than 0.4 c.c. of $1: 2,000,000$. IV : Weaker than 0.4 c.c. of $1: 1,000,000$; far stronger than $\mathrm{V}$.

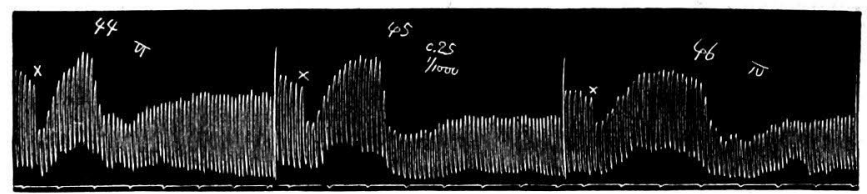

Fig. 4. o. VI : Decidedly weaker than 0.4 c.c. of $1: 1,000,000$; weaker than 0.25 c.c. of $1: 1,000,000$. IV : Stronger than 0.25 c.c. of $1: 1,000,000$.

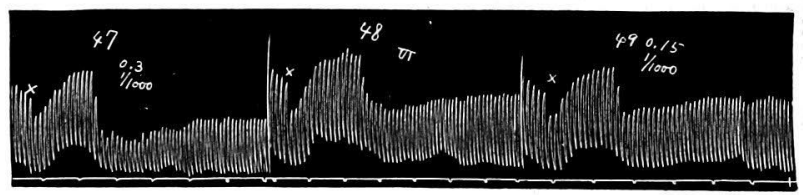

Fig. 4. p. IV : Weaker than 0.3 c.c. of $1: 1,000,000$. VI: Weaker than 0.3 c.c. of $1: 1,000,000$; a little stronger than or almost as strong as 0.15 c.c. of $1: 1,000,000$.

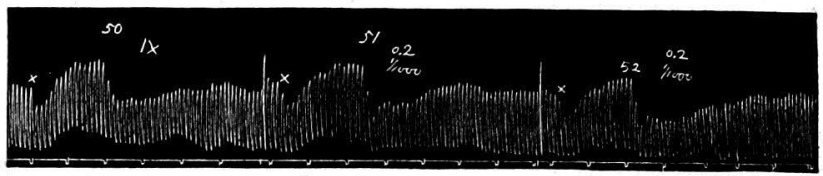

Fig. 4. q. IX : Stronger than 0.15 c.c. of $1: 1000,000$; almost as strong as or a little stronger than 0.2 c.c. of $1: 1,000,000$.

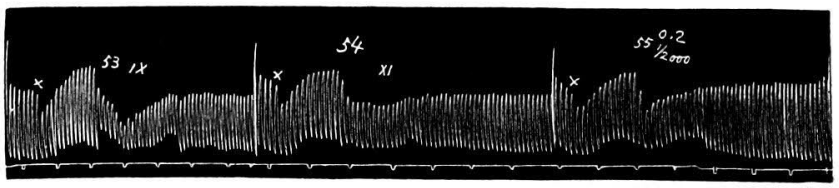

Fig. 4. r. IX : Almost as strong as 0.2 c.c. of $1: 1,000,000$. XI : Stronger than 0.2 c.c. of $1: 2,000,000$; almost as strong as IX. 


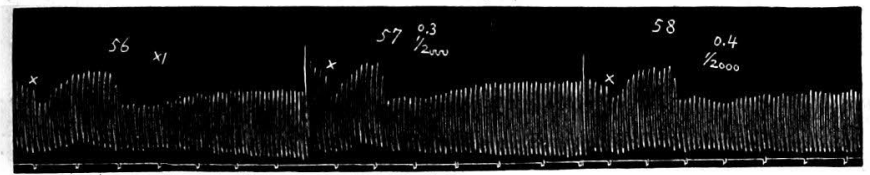

Fig. 4. s. $\mathrm{XI}$ : Stronger than 0.2 c.c. and 0.3 c.c. of $1: 2,000,000$; almost as strong as 0.4 c.c. of $1: 2,000,000$.

To sum up :

I : Weaker than 0.2 c.c. of $1: 2,000,000$; almost as strong as 0.05 c.c. of $1: 2,000,000$; weaker than 0.1 c.c. of $1: 2,000,000$; as strong as $I^{\prime}$. I was assayed at $0.00005 \mathrm{mgrm}$. in 1 c.c.

$I^{\prime}$ : Almost as strong as 0.05 c.c. of $1: 2,000,000$; as strong as $I$. I' was assayed at 0.00005 mgrm. in 1 c.c.

II : Almost as strong as 0.05 c.c. of $1: 2,000,000$; almost as strong as II'. II was assayed at $0.00005 \mathrm{mgrm}$. in 1 c.c.

$\mathrm{II}^{\prime}$ : Almost as strong as II; a little weaker than 0.1 c.c. of $1: 2,000,000$; weaker than III. II' was assayed at $0.00005 \mathrm{mgrm}$. in 1 c.c.

III : Stronger than II'; weaker than IV; almost as strong as 0.2 c.c. of $1: 2,000,000$; weaker than 0.3 c.c. of $1: 2,000,000$. III was assayed at $0.0002 \mathrm{mgrm}$. in 1 c.c.

IV : Stronger than III; stronger than V (two assays); weaker than 0.4 c.c. of $1: 1,000$, 000 ; stronger than 0.25 c.c. of $1: 1,000,000$; weaker than 0.3 c.c. of $1: 1,000,000$. IV was taken as $0.00055 \mathrm{mgrm}$. in 1 c.c.

V: Weaker than IV (two assays); weaker than VI; almost as strong as or a little stronger than 0.3 c.c. of $1: 2,000,000$; stronger than 0.2 c.c. of $1: 2,000,000$; far weaker than 0.4 c.c. of $1: 2,000,000$. $V$ was assayed at $0.0003 \mathrm{mgrm}$. in 1 c.c.

VI : Stronger than V; stronger than VII; weaker than 0.25 c.c. of $1: 1,000,000$; weaker than 0.3 c.c. of $1: 1,000,000$; a little stronger than 0.15 c.c. of $1: 1,000,000$. IV was taken as 0.0004 mgrm. in 1 c.c.

VII : Weaker than VI, almost as strong as 0.2 c.c. of $1: 2,000,000$; weaker than 0.4 c.c. of $1: 2,000,000$. It was assayed at $0.0002 \mathrm{mgrm}$. in 1 c.c.

VIII : Weaker than IX; weaker than 0.2 c.c. of $1: 2,000,000$; stronger than 0.1 c.c. of $1: 2,000,000$; almost as strong as 0.15 c.c. of $1: 2,000,000$. It was assayed at 0.0001 mgrm. in 1 c.c.

IX : Stronger than VIII; stronger than $\mathrm{X}$; stronger than 0.15 c.c. of $1: 1,000,000$; almost as strong as or very little stronger than 0.2 c.c. of $1: 1,000,000$; almost as strong as 0.2 c.c. of $1: 1,000,000$; as strong as XI. It was assayed at $0.0004 \mathrm{mgrm}$. in 1 c.c.

$\mathrm{X}$ : Weaker than $\mathrm{XI}$; weaker than IX; almost as strong as 0.1 c.c. of $1: 2,000,000$. It was assayed at $0.0001 \mathrm{mgrm}$. in 1 c.c.

$\mathrm{XI}$ : Stronger than $\mathrm{X}$; stronger than $\mathrm{XII}$; almost as strong as IX; stronger than 0.2 c.c. of $1: 2,000,000$ (two assays) ; stronger than 0.3 c.c. of $1: 2,000,000$; almost as strong as 0.4 c.c. of $1: 2,000,000$. It was assayed at $0.0004 \mathrm{mgrm}$. in 1 c.c.

$\mathrm{XII}$ : Weaker than XI; weaker than 0.2 c.c. of $1: 2,000,0<0$ (two assays); stronger than 0.1 c.c. of $1: 2,000,000$. XII was taken as $0.00015 \mathrm{mgrm}$. in 1 c.c.

$\mathrm{XII}^{\prime}$ : Almost as strong as $0.2 \mathrm{cc}$. of $1: 2,000,000$; a little stronger than $\mathrm{X}$. It was assayed at $0.0002 \mathrm{mgrm}$. in 1 c.c. 
28. I. 1926,

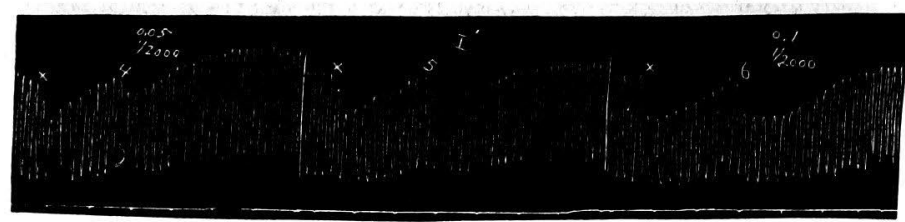

Fig. 5. (All the tracings are reduced to $\left.\frac{1}{2}\right)^{*}$ a. $I^{\prime}:$ Almost as strong as 0.05 c.c. of $1: 2,000,000$; a little weaker than 0.1 c.c. of $1: 2,000,000$.

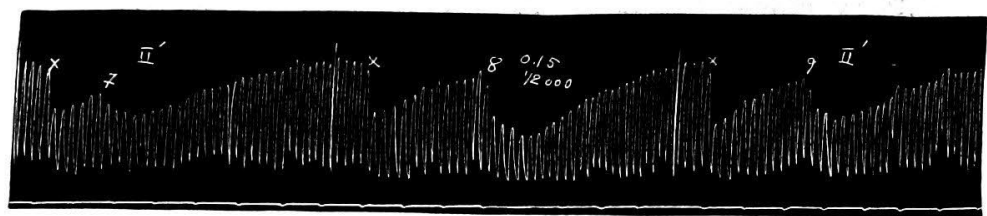

Fig. 5. b. II' : A little weaker than 0.15 c.c. of $1: 2,000,000$ (two assays); almost as strong as 0.1 c.c. of $1: 2,000,000$ (two assays).

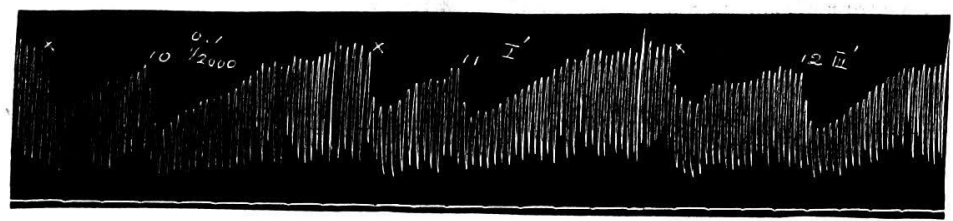

Fig. 5. c. $I^{\prime}$ : Slightly weaker than 0.1 c.c. of $1: 2,000,000$. III': Stronger than $I^{\prime}$; very slightly weaker than 0.1 c.c. of $1: 2,000,000$.

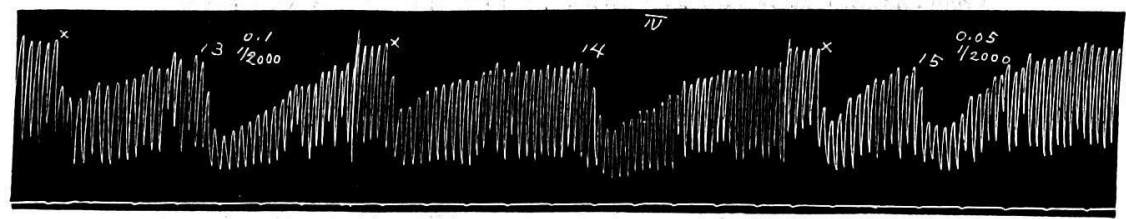

Fig. 5. d. IV : A little weaker than 0.1 c.c. of $1: 2,000,000$; slightly stronger than 0.05 c.c. of $1: 2,000,000$.

* See the foot-note on p. 12. The quantities of the suprarenal vein blood specimens and the indifferent blood in adrenaline blood solutions used for one tracing were always 0.5 c.c. 


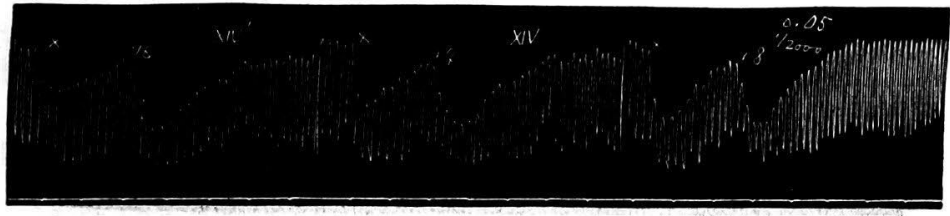

Fig. 5. e. XIV!: Quite as strong as XIV; slightly stronger than 0.0 éc.c. of $1: 2,000$, 000 ; slightly weaker than 0.1 c.c. of $2,000,000$ (Obs. 19).

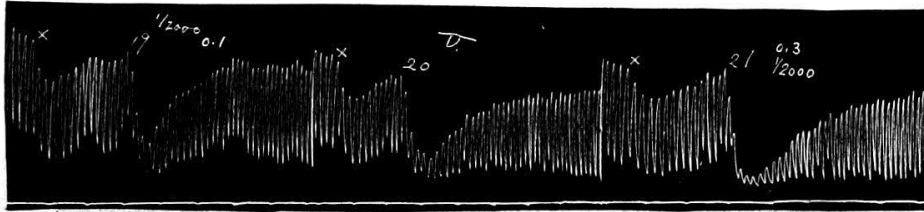

Fig. 5.f. V : Stronger than 0.1 c.c. of $1: 2,000,000$; weaker than 0.3 c.c: of $1: 2,000$, 000 .

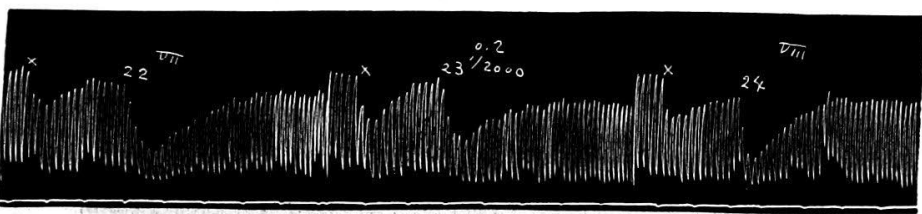

Fig. 5. g. VII : Weaker than 0.3 c.c. and stronger than 0.2 c.c. of $1: 2,000,000$. VIII : Weaker than 0.2 c.c. of $1: 2,000,000$; almost as strong as 0.15 c.c. of $1: 2,000,000$.

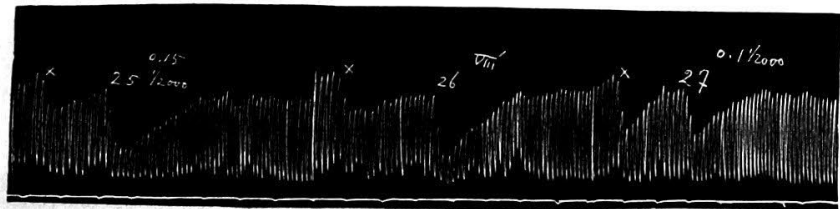

Fig. 5. h. VIII' : Almost as strong as 0.15 c.c. of $1: 2,000,000$; stronger than 0.1 c.c. of $1: 2,000,000$; almost as strong as VIII.

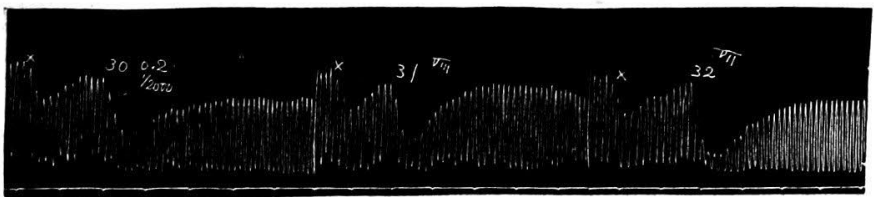

Fig. 5. i. VIII : Weaker than 0.2 c.c. of $1: 2,000,000$; decidedly weaker than VII. (From Obs. 30 another new intestine strip of the same rabbit was employed). 


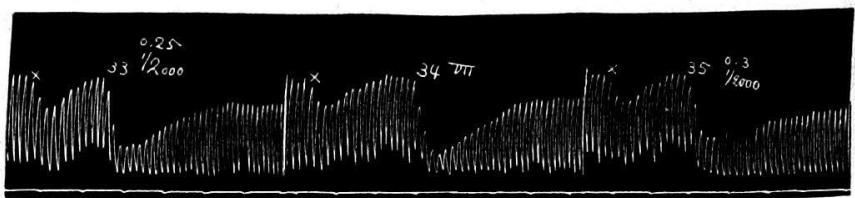

Fig. 5. j. VII : Almost as strong as 0.25 c.c. of $1: 2,000,000$; weaker than 0.3 c.c. of $1: 2,000,000$.

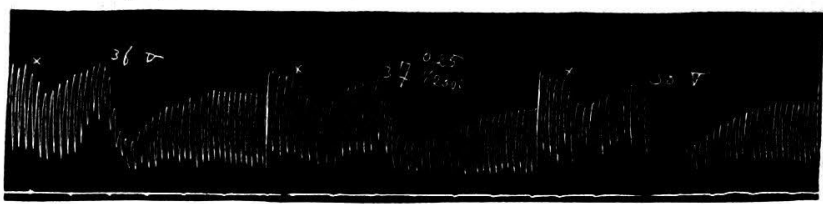

Fig. 5. k. V: Weaker than 0.3 c.c. and almost as strong as or very slightly weaker than 0.25 c.c. of $1: 2,000,000$; stronger than VI.

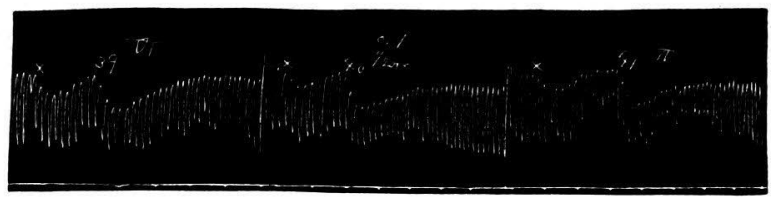

Fig. 5. 1. VI : A little weaker than 0.1 c.c. of $1: 2,000,000$; weaker than V. IV : A little weaker than or almost as strong as 0.1 c.c. of $1: 2,000,000$ ( 2 assays).

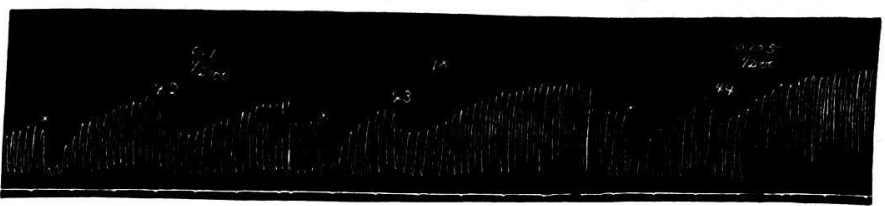

Fig. 5. m. IX: Weaker than 0.1 c.c. and stronger than 0.05 c.c. of $1: 2,000,000$.

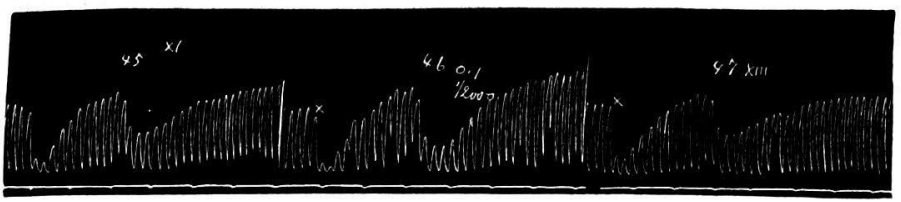

Fig. 5. n. XI: Stronger than 0.05 c.c. and 0.1 c.c. of $1: 2,000,000$. XIII : Stronger than 0.1 c.c. of $1: 2,000,000$; almost as strong as 0.15 c.c. of $1: 2,000,000$. 


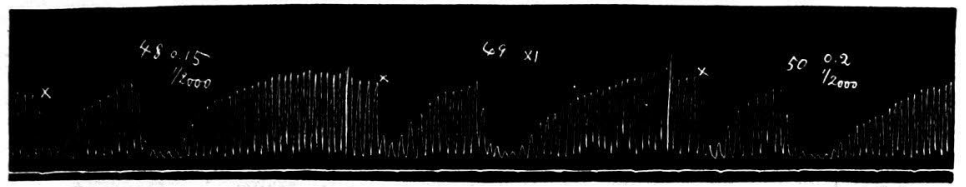

Fig. 5. o. XI : Stronger than 0.15 c.c. of $1: 2,000,000$; weaker than 0.2 c.c. of $1: 2,000$, 000.

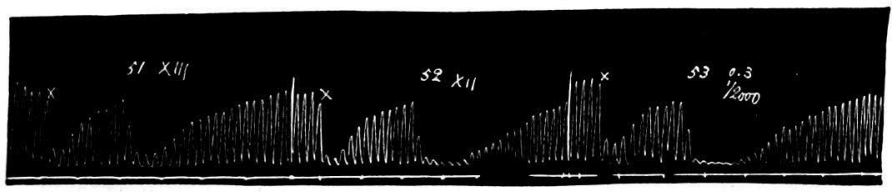

Fig. 5. p. XIII : Weaker than 0.2 c.c. of $1: 2,000,0$ c0; weaker than XII. XII : Stronger than XIII; stronger than 0.3 c.c. of $1: 2,000,000$.

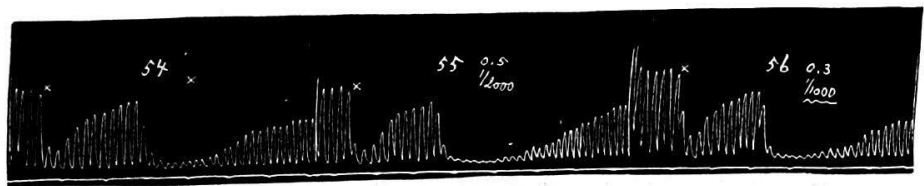

Fig. 5. q. X : Stronger than 0.3 c.c. of $1: 2,000,0 \mathrm{CO}$; a little stronger than 0.5 c.c. of $1: 2,000,000$; weaker than 0.3 c.c. of $1: 1,000,000$.

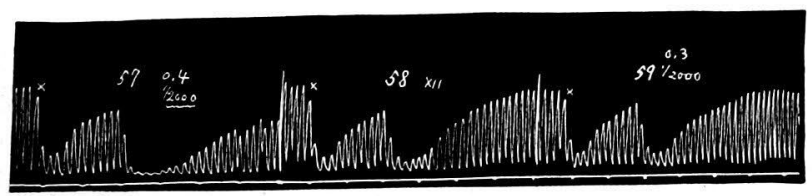

Fig. 5. r. XII : Weaker than 0.4 c.c. of $1: 2,0 c 0,000$; slightly stronger than 0.3 c.c. of $1: 2,000,000$.

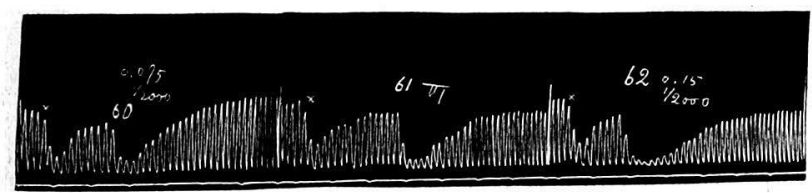

Fig. 5. s. VI: Stronger than 0.075 c.c. of $1: 2,000,000$; weaker than 0.15 c.c. of $1: 2,000$, 000. 


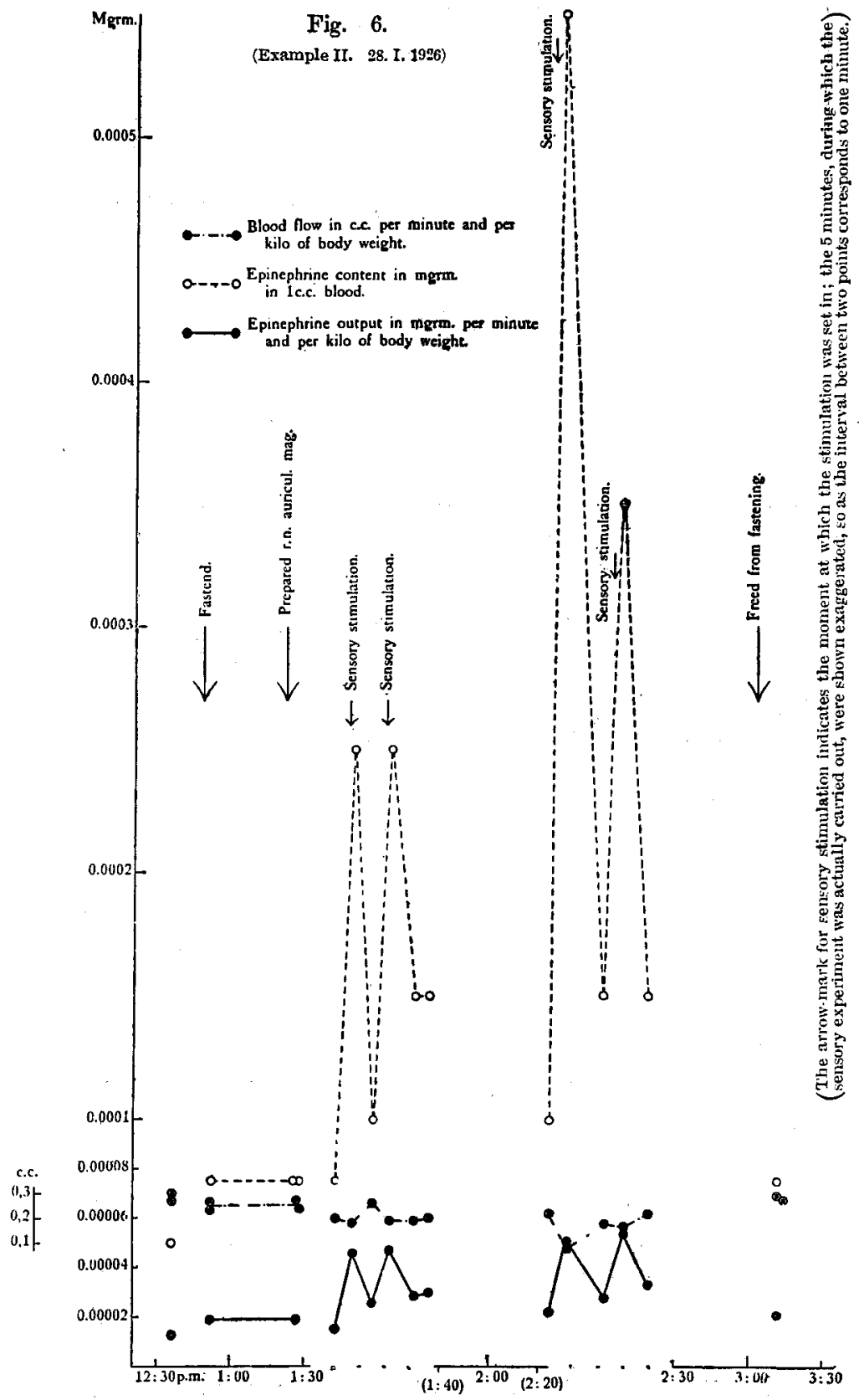




\section{To sum up :}

$I^{\prime}:$ Almost as strong as 0.05 c.c. of $1: 2,000,000 ;$ a little weaker than 0.1 c.c. of $1: 2,000$, 000 (two assays); weaker than III'. I' was assayed at $0.00005 \mathrm{mgrm}$. in 1 c.c.

$\mathrm{II}^{\prime}$ : A little weaker than 0.15 c.c. of $1: 2,000,000$ (two assays); almost as strong as 0.1 c.c. of $1: 2,000,000$ (two assays). It was assayed at $0.0001 \mathrm{mgrm}$. in 1 c.c.

III': Stronger than $I^{\prime} ;$ very slightly weaker than 0.1 c.c. of $1: 2,000,000$. : It was taken as $0.000075 \mathrm{mgrm}$. in 1 c.c.

IV : A little weaker than 0.1 c.c. of $1: 2,000,000$ (two assays); slightly stronger than 0.05 c.c. of $1: 2,000,000$. It was assayed at $0.000075 \mathrm{mgrm}$. in 1 c.c.

V: Stronger than 0.1 c.c. of $1: 2,000,000$;-stronger than VI; weaker than 0.3 c.c. of $1: 2,000,000$ (two assays); almost as strong as or very slightly weaker than 0.25 c.c. of $1: 2,000,000$. $V$ was taken as 0.00025 mgrm. in 1 c.c.

VI: Weaker than V; a little weaker than or almost as strong as 0.1 c.c. of $1: 2,000$, 000 ; stronger than 0.075 c.c. of $1: 2,000,000$; weaker than 0.15 c.c. of $1: 2,000,000$. It was taken as $0.000 \mathrm{r}$ mgrm. in 1 c.c.

VII :- Almost as strong as 0.25 c.c. of $1: 2,000,000$; weaker than 0.3 c.c. of $1: 2,000,000$ (two assays); stronger than VIII; stronger than 0.2 c.c. of $1: 2,000,000$. VII was assayed at $0.00025 \mathrm{mgrm}$, in 1 c.c.

VIII : Weaker than 0.2 c.c. of $1: 2,000,000$ (two assays); almost as strong as 0.15 c.c. of $1: 2,000,000$; decidedly weaker than VII. It was assayed at $0.00015 \mathrm{mgrm}$. in 1 c.c.

VIII': Almost as strong as 0.15 c.c. of $1: 2,000,000$; stronger than 0.1 c.c. of $1: 2,000$; 000 ; alnost as strong as VIII. It was assayed at $0.00015 \mathrm{mgrm}$. in 1 c.c.

IX: Weaker than 0.1 c.c. of $1: 2,000,000$; stronger than 0.05 c.c. of $1: 2,000,000$. It was taken as $0.000075 \mathrm{mgrm}$. in 1 c.c.

$X$ : Stronger than 0.3 c.c. of $1: 2,000,000$; stronger than 0.5 c.c. of $1: 2,000,000$; weaker than 0.3 c.c. of $1: 1,000,000$. It was taken as $0.00055 \mathrm{mgrm}$. in 1 c.c.

$\mathrm{XI}$ : Stronger than 0.05 c.c. of $1: 2,000,000$; stronger than 0.1 c.c. of $1: 2,000,000$; stronger than 0.15 c.c. of $1: 2,000,000$; weaker than 0.2 c.c. of $1: 2,000,000$. It was taken as $0.000175 \mathrm{mgrm}$. in 1 c.c.

XII : Stronger than XIII; stronger than 0.3 c.c. of 1 : $2,000,000$; weaker than 0.4 c.c. of $1: 2,000,000$; slighily stronger than 0.3 c.c. of $1: 2,000,000$. XII was taken as 0.00035 mgrm. in 1 c.c.

XIII : Weaker than XII ; weaker than 0.2 c.c. of $1: 2,000,000$; stronger than 0.1 c.c. of $1: 2,000,000$ : almost as strong as 0,15 c.c. of $1: 2,000,000$. It was assayed at 0.00015 mgrm. in 1 c.c.

XIV : Quite the same with XIV'; slightly stronger than 0.05 c.c. of $1: 2,000,000$; slightly weaker than 0.1 c.c. of $1: 2,000,000$. XIV and XIV' were taken as $0.000075 \mathrm{mgrm}$. in 1 c.c.

circumvented by one or two laboratory servants forcing the animal down at the shoulder or sometimes moreover on its haunches.

In nine out of thirteen dogs listed in the table, the sensory experiment was performed in succession to the fastening experiments. During the fastening down the great auricular nerve or the median nerve on one side (the right as a rule) was prepared for stimulation. The preparing evoked invariably violent reactive movements ; the dog yelled, struggled, attempted 
to bite the operator's hands, and also to get free from confinement, and sometimes micturition, regardless of whether the animal was already excited during the fastening alone or behaved calmly. Some time was allowed to elapse for subsidence of the excitement incident to preparation of the nerve; sometimes it was sufficient so that the specimen subsequently taken was indistinguishable in any way from those drawn prior to the uncovering of the nerve, but sometimes the first specimen taken following the preparation portrayed an unmistakably increased liberation of epinephrine.

Some samples were then successively collected, indeed alternately during the rest spell and during the stimulation period. The nerve was continuously stimulated by means of the induction current. The reactions to the nerve stimulation were as a matter of fact very violent, more violent in the present investigations, where the animal was fastened prone, somewhat near to the natural posture than the fastening in supine position, in comparison with cases in which the animal was fixed supine and the cava pocket was equipped without being anaesthetized. Such a series of stimulation experiments was usually repeated twice. In some cases some last samples were taken from the animals, freely behaving themselves after being freed from fastening.

On eight dogs 28 stimulation experiments were carried out, and the stimulation occasioned an acceleration of epinephrine output in all the dogs save one (Dog 11).

The acceleration was evident in Dogs 2(5-8 fold output of the initial was produced by stimulation), 3(three fold), 7(2-2.5 fold), 10(3-5 fold), 12(2 fold or more) and 13(2-3 fold), while in 2 dogs (Dogs 5 and 6 ) the stimulation could not double the rate of output during the rest intervals. In Dog 5 the last stimulation accelerated the output largely (From 0.0000 $23 \mathrm{mgrm}$. per kilo and per minute to $0.000074 \mathrm{mgrm}$.). In Dog 11 the outputs of epinephrine under nerve excitation, which produced the usual violent reaction, were found not materially to differ from those of the rest spell subsequent to the nerve preparing. The rate of discharge in the free period as well as in the fastening period previous to the nerve uncovering was really somewhat small. Preparing of the great auricular nerve was followed by an increased output of epinephrine.

The augmentation of output rate evoked by the sensory stimulation is indeed due solely or mainly to an increase of the epinephrine concentration in the suprarenal vein blood, the velocity of the blood current through the gland being estimated as unaltered or only a little hastened. A faster flow of blood was observed only in Dogs 2, 3 and 5 (only in the last stimulation 
period) during the stimulation, while in the rest the outflow of blood remained unchanged or sometimes rather a little reduced. At any rate the velocity of the blood current underwent changes only on a small scale.

Among the previous sensory experiments with the non-anaesthetized dogs equipped with the cava pocket there were 5 negative cases in which the sensory stimulation was accompanied by no acceleration of rate of epinephrine output, out of 37 stimulation experiments reported by Kodama and 1 negative instance out of 24 examples listed in the paper of Sugawara, Watanabé and Saito; and the epinephrine output during the stimulation periods was 2-5 times that of the rest intervals. The results in the present investigations are in entire accord, in these respects, with the previous reports ; namely 2 negative examples contrast against 26 positives and under the stimulation the output rate became twice to fivefold as rapid as that in the non-stimuli periods; only in one dog a rate eight times faster was induced by the stimulation.

Notwithstanding entire agreements between the previous data and the present investigations are to be readily seen as thus establishing, we soon came to find a striking contrast between them. Though both sets of results agree well in the percentile difference of the output rate between the stimulation periods and the rest intervals, the absolute rate of discharge estimated under the nerve stimulation in the previous studies is far greater than that of the same nature obtained in the present researches. That the output during the rest spells in the non-anaesthetized dogs equipped with the lumbar route preparation is far inferior to that detected in the cava pocket experiments with the non-narcotized ones has already been referred to in the foregoing communication.

That in Dog 7 the first fastening induced an enormously rapid output of epinephrine sinultaneously with unusual furious excited state is as has been repeatedly quoted abore.

That the sensory stimulation is capable of accelerating the epinephrine output, as a rule, at a certain ratio with the rate of output prevailing prior to application of stimuli upon the sensory nerve is certainly a striking and interesting fact. At present we have no available explanation to offer for this fact.

It may be, however, tentatively explained by assuming that an increase of excitability takes place in the centrum or centra concerning the epinephrine liberation, being looked at as a whole, with the prevailing stimulation besides the actual excitement of the centrum or centra.

In view of this fact an explanation suggested by some writers that an 
increase of the epinephrine discharge, which might be already introduced by the necessary conditions inherent in preparing the cava pocket may mask the effect of sensory stimulation etc., is entirely untenable. What was presumably the sole or chief factor which really masked the effect of sensory stimuli upon the epinephrine output in the experiments with anaesthetized animals has been often discussed in the previous papers from this laboratory.

\section{SumMaRY.}

I. The Iumbar route operation, described in the foregoing paper, was performed on dogs, the operation field of which was previously deafferented, either prone fastened on the table or freely sitting or standing there. As a matter of course narcosis nas never resorted to. Making use of these dogs the bloods were collected from the suprarenal gland during the fastening period and the free interval alternately, and compared each other. In half of the cases the fastening down induced an evident increase in the output rate of epinephrine, though the degree of acceleration was somewhat inferior to that in the sensory stimulation experiments. In them the violent reactions against fastening, as yelling, struggling, were simultaneously manifest. In the rest the fastening failed to hasten the output velocity of epinephrine. In half of the latter instances the dogs were almost quiet during the confinement.

II. Sensory stimulation was also again tried on some dogs in succession to the fastening experimentation. In almost all cases the stimulation of the sensory nerve called forth a faster rate of epinephrine liberation. The rate under stimuli was nearly $2-5$ times as fast as that of the rest spells, seldom 8 times. Of the constancy in occurrence of accelerating effect and the ratio of augmentation to the rate during the rest interval the present results achicved with the lumbar route method coincide well with those obtained with the cava pocket method on non-anaesthetized dogs, but the absolute values of the rates during the spells of rest as well as stimuli in the present investigation are far inferior to the previous results with the cava pocket.

While this paper was in the press a recent paper of W. B. Cannon and S. W. B riton (Am. J. Physiol., 1927, 79, 433) fell into our hands. That the fastening in variably accelerated the rate of the denervated heart of the $c$ at seems to harmonize with the reaction of that species of animal to the fastening in regard to the carbolydrate metabolism. 